\title{
Interdomain Cytoplasmic Interactions Govern the Intracellular Trafficking, Gating, and Modulation of the Kv2.1 Channel
}

\author{
Durga P. Mohapatra, ${ }^{1}$ Dominic F. Siino, ${ }^{1}$ and James S. Trimmer ${ }^{1,2}$ \\ ${ }^{1}$ Department of Neurobiology, Physiology and Behavior, College of Biological Sciences, and 2Department of Physiology and Membrane Biology, School of \\ Medicine, University of California, Davis, Davis, California 95616
}

\begin{abstract}
Voltage-gated potassium (Kv) channels comprise four transmembrane $\alpha$ subunits, often associated with cytoplasmic $\beta$ subunits that impact channel expression and function. Here, we show that cell surface expression, voltage-dependent activation gating, and phosphorylation-dependent modulation of Kv2.1 are regulated by cytoplasmic N/C interaction within the $\alpha$ subunit. Kv2.1 surface expression is greatly reduced by C-terminal truncation. Tailless Kv2.1 channels exhibit altered voltage-dependent gating properties and lack the bulk of the phosphorylation-dependent modulation of channel gating. Remarkably, the soluble $\mathrm{C}$ terminus of Kv2.1 associates with tailless channels and rescues their expression, function, and phosphorylation-dependent modulation. Soluble $\mathrm{N}$ and $\mathrm{C}$ termini of Kv2.1 can also interact directly. We also show that the N/C-terminal interaction in Kv2.1 is governed by a 34 aa motif in the juxtamembrane cytoplasmic $\mathrm{C}$ terminus, and a 17 aa motif located in the $\mathrm{N}$ terminus at a position equivalent to the $\beta$ subunit binding site in other $\mathrm{Kv}$ channels. Deletion of either motif disrupts N/C-terminal interaction and surface expression, function, and phosphorylationdependent modulation of Kv2.1 channels. These findings provide novel insights into intrinsic mechanisms for the regulation of Kv2.1 trafficking, gating, and phosphorylation-dependent modulation through cytoplasmic N/C-terminal interaction, which resembles $\alpha / \beta$ subunit interaction in other Kv channels.
\end{abstract}

Key words: hippocampal neurons; potassium channel; assembly; immunocytochemistry; electrophysiology; phosphorylation

\section{Introduction}

Voltage-gated potassium (Kv) channels play a crucial role in maintaining cellular ionic homeostasis and regulating neuronal excitability (Pongs, 1999). Kv2.1 is an abundant delayed rectifier type $\mathrm{Kv}$ channel expressed in most central neurons (Murakoshi and Trimmer, 1999; Antonucci et al., 2001; Malin and Nerbonne, 2002), where it is found at high densities in large somatodendritic clusters (Trimmer, 1991; Hwang et al., 1993; Scannevin et al., 1996). Knock-down of Kv2.1 in rat hippocampal neurons, where it contributes the majority of $I_{\mathrm{K}}$ currents (Murakoshi and Trimmer, 1999), leads to enhanced excitability, especially during highfrequency synaptic transmission, suggesting a critical role for Kv2.1 in regulating membrane excitability (Du et al., 2000).

$\mathrm{Kv}$ channels are grouped in 12 major subfamilies [Kv1-Kv12 (Gutman et al., 2005)] and are transmembrane protein complexes comprising four pore-forming and voltage-sensing $\alpha$ subunits, which in the case of Kv1 and Kv4 subfamilies are associated

\footnotetext{
Received Jan. 15, 2008; revised March 28, 2008; accepted March 31, 2008.

This work was supported by National Institutes of Health-National Institute of Neurological Disorders and Stroke Grant NS42225 (J.S.T.). We thank Evgenia Kalashnikova and Dr. Elva Diaz for providing cultured hippocampal neurons, Dr. Kang-Sik Park for advice on co-IP experiments, Dr. Klaus Benndorf for the generous gift from Kv2.1-Kv1.2 chimeras, and Drs. JoAnne Engebrecht and Jie Zheng for critical comments on this manuscript.

Correspondence should be addressed to Dr. James S. Trimmer, Department of Neurobiology, Physiology and Behavior, College of Biological Sciences, 196 Briggs Hall, University of California, One Shields Avenue, Davis, CA 95616-8519. E-mail: jtrimmer@ucdavis.edu.

DOI:10.1523/JNEUROSCI.0186-08.2008

Copyright $\odot 2008$ Society for Neuroscience $\quad 0270-6474 / 08 / 284982-13 \$ 15.00 / 0$
}

with cytoplasmic auxiliary “ $\beta$ ” subunits (Li et al., 2006). Kv channel $\alpha$ subunits have six transmembrane segments S1-S6 arranged in modular voltage-sensing (S1-S4) and pore-forming (S5-S6) domains, and extensive $\mathrm{N}$ - and C-terminal cytoplasmic domains (Long et al., 2005). The $\mathrm{N}$ terminus contains the tetramerization or T1 domain that mediates subfamily-specific $\alpha$ subunit tetramerization (Papazian, 1999). Kv $\beta$ auxiliary subunits of $\mathrm{Kv} 1$ channels also bind within the T1 domain (Sewing et al., 1996; Yu et al., 1996; Gulbis et al., 2000) to influence intracellular trafficking (Shi et al., 1996; Campomanes et al., 2002), voltagedependent gating ( $\mathrm{Li}$ et al., 2006), and phosphorylationdependent modulation (Gong et al., 1999), and to determine polarized trafficking ( $\mathrm{Gu}$ et al., 2003). Kv4 channels also have cytoplasmic auxiliary $\beta$ subunits named Kv4 channel interacting proteins (KChIPs) that bind to the $\mathrm{N}$ terminus of $\mathrm{Kv} 4 \alpha$ subunits and perform similar roles (An et al., 2000; Schrader et al., 2002; Shibata et al., 2003; Jerng et al., 2004).

Auxiliary $\beta$ subunits have not been identified in Kv2.1 channels. Previous studies suggested, however, that the cytoplasmic C terminus of Kv2.1 was an important determinant of channel function, by influencing the voltage-dependent gating of Kv2.1 (Ju et al., 2003; Scholle et al., 2004) and determining its polarized expression and clustering (Scannevin et al., 1996; Lim et al., 2000). Voltage-dependent gating and clustering of Kv2.1 are also regulated by phosphorylation (Misonou et al., 2004, 2005; Mohapatra and Trimmer, 2006) at C-terminal phosphorylation sites 
(Park et al., 2006). The mechanism of gating modulation by C-terminal phosphorylation is not known.

Here, we show that direct Kv2.1 N/C interaction is necessary for efficient intracellular trafficking of Kv2.1 channels to the cell surface, for normal voltage-dependent gating, and for phosphorylation-dependent modulation of gating. We find that the soluble Kv2.1 C terminus can associate with a tailless Kv2.1 mutant via its cytoplasmic $\mathrm{N}$ terminus and reconstitute proper tetrameric assembly, intracellular trafficking, and phosphorylation-dependent modulation. We define the Kv2-specific motifs that mediate N/C interaction and find that the Kv2.1 C terminus interacts with the $\mathrm{N}$ terminus in a manner similar to that of auxiliary $\beta$ subunits with Kv1 and Kv $4 \alpha$ subunits.

\section{Materials and Methods}

Generation of Kv2.1 mutants and chimeras. Various truncation and internal deletion mutants at the cytoplasmic N- and C-terminal domains of recombinant rat Kv2.1, rat Kv1.4, and rat Kv4.3long were generated following standard molecular biology methods as described previously (Scannevin et al., 1996; Lim et al., 2000). A methionine residue was incorporated at the beginning of the Kv2.1 N-terminal truncation constructs, $\Delta \mathrm{N} 40, \Delta \mathrm{N} 60, \Delta \mathrm{N} 120$, and $\Delta \mathrm{N} 130$. No methionine residue was incorporated at the beginning of Kv2.1 C-terminal constructs. Although they were constructed as nucleotide sequence corresponding to amino acid residues from 411 to 853 , the actual start point is at residue M444, the first corresponding $5^{\prime}$-ATG sequence in these constructs. Kv2.1$\Delta$ C416-Kv1.2-S4-S5 chimera was generated from the chimera of Kv2.1 with S4-S5 sequence of Kv1.2 (Scholle et al., 2004).

Culture and transfection of COS and HEK cells. COS-1 and human embryonic kidney 293 (HEK293) cells (American Type Culture Collection, Manassas, VA) were cultured and transiently transfected with plasmids encoding the recombinant wild-type (WT), mutant, or soluble fragments of Kv2.1, Kv1.4, or Kv4.3 in pRBG4 plasmids, using Lipofectamine 2000 (Invitrogen, Carlsbad, CA) according to the manufacturer's instructions and as described previously (Mohapatra and Trimmer, 2006). Cells were incubated with Lipofectamine-containing transfection mixture for $6 \mathrm{~h}$ in serum/antibiotic-free culture media, after which the cells were rinsed twice and incubated in the serum/antibiotic-containing media. Transfected cells were used for experiments within 42-48 h after transfection. For electrophysiological experiments, the cells were cotransfected with pEGFPcl plasmid (Clontech, Mountain View, CA) to identify the transfected cells under epifluorescence. The transfection efficiencies were typically $60-80 \%$. We have used COS- 1 cells for the bulk of the immunocytochemical experiments because of their advantageous morphology for imaging the rough endoplasmic reticulum (RER) and cell surface Kv2.1 pools, and HEK cells for electrophysiology and biochemistry experiments because they offer the advantage of a more robust phosphorylation of Kv2.1 (Mohapatra and Trimmer, 2006; Park et al., 2007).

Culture and transfection of rat embryonic hippocampal neurons. Embryonic rat hippocampal neurons [from embryonic day 18 (E18)/E19 embryos] were isolated and cultured on poly-L-lysine-coated glass coverslips as described previously (Misonou et al., 2004; Mohapatra and Trimmer, 2006). The cultured hippocampal neurons (CHNs) were transfected on the eighth day in vitro with the Kv2.1-WT or HA-Kv2.1$\Delta \mathrm{C} 416$ and $\mathrm{Kv} 2.1 \mathrm{C}$-myc constructs $(0.5 \mu \mathrm{g}$ each) alone or in combination (ratio, 1:1) using Lipofectamine 2000 (Invitrogen) according to the manufacturer's instructions, and used $3 \mathrm{~d}$ later. Before the addition of Lipofectamine-containing transfection mixture, the glass coverslips with attached CHNs were transferred from the astrocyte conditioned media to new six-well plates containing modified Eagle's medium (MEM) and incubated for $30 \mathrm{~min}$ at $37^{\circ} \mathrm{C}$ in a humidified incubator with $5 \% \mathrm{CO}_{2}$. $\mathrm{CHNs}$ were incubated with the transfection mixture in MEM for $6 \mathrm{~h}$, after which the coverslips were rinsed twice with MEM and transferred to astrocyte-conditioned media and incubated in the $\mathrm{CO}_{2}$ incubator for $3 \mathrm{~d}$. For electrophysiological experiments, the neurons were cotransfected with pEGFPcl plasmid.
Immunofluorescence staining of transfected neurons or mammalian cell lines expressing different channel constructs. COS- 1 and HEK293 cells, and CHNs transiently expressing the recombinant rat Kv2.1-WT, different truncation, deletion mutants and chimeric channels of Kv2.1, Kv4.3, and Kv1.4 were grown on glass coverslips and paraformaldehyde-fixed, detergent-permeabilized (with Triton X-100) and immunostained as described previously (Mohapatra and Trimmer, 2006). The rabbit polyclonal antibodies used as primary antibodies were anti-Kv2.1e, generated against the S1-S2 extracellular region of Kv2.1 (Lim et al., 2000); KC, generated against the cytoplasmic distal C-terminal end of Kv2.1 (Trimmer, 1991); anti-Kv1.4N, generated against the cytoplasmic N-terminal domain of Kv1.4 (Rhodes et al., 1995); and anti-HA (Zymed, San Francisco, CA). The mouse monoclonal antibodies (mAbs) used as primary antibodies were $\mathrm{K} 39 / 25$, generated against the S1-S2 extracellular region of Kv2.1 (Lim et al., 2000); K89/41, generated against the cytoplasmic distal C-terminal end of Kv2.1 (Antonucci et al., 2001); K75/41, generated against the cytoplasmic C-terminal domain of Kv4.3 (Rhodes et al., 2004); K63/39, generated against the cytoplasmic C terminus of Kv1.4 (J. S. Trimmer, unpublished data); and anti-myc (19E10; American Type Culture Collection). The anti-Kv channel mouse mAbs are available from NeuroMab (www.neuromab.org), a not-for profit supplier of monoclonal antibodies administered through the University of California.

For cell surface staining of Kv2.1, cells were fixed and incubated with the Kv2.1e or K39/25 antibodies after fixation and before detergent permeabilization. Our previous studies (Manganas and Trimmer, 2000; Tiffany et al., 2000; Manganas et al., 2001a,b; Shibata et al., 2003) show that these conditions do not yield staining of S1-S2 epitopes on intracellular Kv channels, for which the antibodies would need to cross both the plasma membrane and the membrane of the organelle (RER, Golgi, etc.) harboring the intracellular channel to react with the S1-S2 binding site. Alexa 488-conjugated or Alexa 594-conjugated anti-mouse or antirabbit secondary antibodies (1:2000; Invitrogen) were used as secondary antibodies. Coverslips containing stained cells were mounted on microscope slides in PBS, pH 9.0, containing $90 \%$ glycerol and $1 \mathrm{mg} / \mathrm{ml}$ $p$-phenylenediamine. Immunofluorescence images were captured with a 24-bit color digital camera coupled to Axiovision software installed on an Axioskop2 microscope with a $63 \times, 1.25$ numerical aperture (NA) PlanNeofluar objective (Carl Zeiss, Jena, Germany). Three-dimensional image analyses of the HEK293 cells were done in a Carl Zeiss Axiovert 200M microscope with a $63 \times, 1.25$ NA Plan-Neofluar objective and an ApoTome structured illumination confocal system, and an Axiocam HRm camera with Axiovision software (Mohapatra and Trimmer, 2006). Cutview images were generated with Axiovision for analyzing intracellular or plasma membrane-associated distribution of membrane proteins (Mohapatra and Trimmer, 2006). All of the images were transferred to PhotoShop software (Adobe Systems, San Jose, CA) as JPEG files. For analyses of surface versus intracellular staining of specific channel proteins, four independent blinded samples of at least 100 cells each were scored for determining the surface or intracellular localization.

Immunoprecipitation of Kv2.1 truncation constructs. Coimmunoprecipitation (co-IP) of Kv2.1- $\Delta \mathrm{C} 416$ and $2.1 \mathrm{C}$ or different $2.1 \mathrm{~N}$ and $2.1 \mathrm{C}$ constructs were performed from 1\% Triton-X-100-lysed HEK293 cells expressing either or each of the truncation constructs as well as HEK293 cells expressing the Kv2.1-WT. Under our experimental conditions, $>80 \%$ of total Kv2.1 from transfected HEK293 cells was in the Tritonsoluble fraction, which was used as the input for subsequent IP reactions. IP reactions were performed using the anti-Kv2.1 rabbit polyclonal antibodies KC, Kv2.1e, or Kv2.1n ( $\sim 5 \mu$ g of antibody for $\sim 1 \mathrm{mg}$ of total lysate protein) followed by incubation with protein G-Sepharose beads (GE Healthcare, Piscataway, NJ). After extensive washing, the IP reaction products were eluted by boiling the beads in SDS sample buffer for 2-3 min. The eluted protein complexes were then separated by SDS-PAGE gels and transferred to nitrocellulose membranes. The membranes were immunoblotted using the Kv2.1 mouse mAbs K89/41 or K39/25, as detailed in the respective figure legends. Immunoblots were incubated with HRP-conjugated anti-mouse secondary antibodies (Antibodies, Davis, CA), followed by ECL (PerkinElmer, Waltham, MA). The Kv2.1-WT, 
Kv2.1- $\Delta$ C416, or different Kv2.1C immunoreactive bands on the membrane were visualized by exposing to x-ray film (Kodak, Rochester, NY).

Sucrose-density gradient sedimentation of Kv2.1 WT and truncation/ deletion mutants. Sucrose-density gradient sedimentation of Kv2.1-WT and truncation/deletion proteins was performed as described previously (Manganas et al., 2001a,b). HEK293 cells expressing Kv2.1-WT and either or each of the truncation constructs were lysed with the lysis buffer containing $1 \%$ Triton X-100 as described previously (Mohapatra and Trimmer, 2006). Under our experimental conditions, $>80 \%$ of total Kv2.1 from transfected HEK293 cells was present in the Triton-soluble fraction, which was used as the input for sucrose density gradient sedimentation experiments. The Triton-X-100-solubilized lysates $(50 \mu \mathrm{l})$ were layered on top of separate linear nondenaturing $5-50 \%$ sucrose gradients $(1.5 \mathrm{ml})$ containing the same lysis buffer and protease inhibitor mixture. To yield monomeric Kv2.1-WT $\alpha$-subunits, an aliquot of the lysate was heat-denatured in the presence of reducing agent $(\beta$ mercaptoethanol). Samples were centrifuged for $4 \mathrm{~h}$ at 202,059 $\times g$ at $4^{\circ} \mathrm{C}$, and $10 \times 155 \mu \mathrm{l}$ fractions were manually collected from the top of the gradient. Each $155 \mu \mathrm{l}$ fraction was added to $155 \mu \mathrm{l}$ of $2 \times$ SDS sample buffer, boiled for $2-3 \mathrm{~min}$, and centrifuged at $5000 \times g$ for $5 \mathrm{~min}$. Samples were analyzed by SDS-PAGE and immunoblot as described above.

Immunoblotting of Kv2.1-WT and $\Delta 55-71$ with phosphospecific antibodies. Kv2.1-WT or Kv2.1 $\Delta 55-71$ expressing HEK293 cell lysates were incubated without or with $100 \mathrm{U} / \mathrm{ml}$ calf thymus alkaline phosphatase (AP) (Roche, Indianapolis, IN) at $37^{\circ} \mathrm{C}$ for $2 \mathrm{~h}$ and resolved by $7.5 \%$ SDS-PAGE followed by blotting onto nitrocellulose membrane as described previously (Mohapatra and Trimmer, 2006). Immunoblots were probed with either the phosphoindependent anti-Kv2.1 rabbit polyclonal antibody $\mathrm{KC}$, or rabbit polyclonal phosphospecific antibodies specific for Kv2.1 phosphorylation sites pS453 (S453P), pS563 (S563P), pS603 (S603P), and pS715 (S715P) as described previously (Misonou et al., 2006; Park et al., 2006). Immunoblots were developed as described above.

Electrophysiology and data analysis. Outward Kv2.1 potassium currents were recorded from COS-1 or HEK293 cells transiently expressing the recombinant WT rat Kv2.1 or truncated Kv2.1 mutants alone or in combination using whole-cell mode of the patch-clamp technique. Similarly, delayed rectifier $\mathrm{K}^{+}\left(I_{\mathrm{K}}\right)$ currents from cultured rat hippocampal neurons transfected with WT and truncated constructs of Kv2.1 alone or in combination were recorded in whole-cell patch-clamp technique. Currents were recorded with an EPC10 patch-clamp amplifier (HEKA Electronik, Lambrecht/Pfalz, Germany), sampled at $10 \mathrm{kHz}$, and filtered at $2 \mathrm{kHz}$ using a digital Bessel filter. All currents were capacitance- and series-resistance compensated, and leak-subtracted by standard $P / n$ procedure. Only current recordings from cells with $<5 \mathrm{~m} \Omega$ (for HEK293 and COS cells) and $<8 \mathrm{~m} \Omega$ (for cultured hippocampal neurons) series resistance were considered for analyses. Cells with $\geq 20 \mathrm{nA}$ peak current amplitude at a $+80 \mathrm{mV}$ voltage pulse were not considered for analyses. Patch pipettes were pulled from borosilicate glass tubing, heat-polished at the tip to give a resistance of $1-2 \mathrm{M} \Omega$ when filled with the pipette solution (in mM: $140 \mathrm{KCl}, 2 \mathrm{MgCl}_{2}, 1 \mathrm{CaCl}_{2}, 5 \mathrm{EGTA}, 10$ glucose, and 10 HEPES, pH 7.3). The extracellular buffer contained the following (in $\mathrm{mm}$ ): $140 \mathrm{NaCl}, 5 \mathrm{KCl}, 2 \mathrm{CaCl}_{2}, 2 \mathrm{MgCl}_{2}, 10$ glucose, and $10 \mathrm{HEPES}, \mathrm{pH}$ 7.3. For neuronal $I_{\mathrm{K}}$ recordings, $100 \mathrm{~nm}$ tetrodotoxin was added in the extracellular buffer to block voltage-gated $\mathrm{Na}^{+}$currents. Calf intestinal AP (Roche) was extensively dialyzed with the pipette solution at $4^{\circ} \mathrm{C}$ overnight using $10 \mathrm{kDa}$ pore size dialysis cassettes (Pierce, Rockford, IL) and diluted in the internal solution to give a final working concentration of $100 \mathrm{U} / \mathrm{ml}$. Extracellular buffers were applied using a polytetrafluorethylene glass multiple-barrel perfusion system.

For determining the current density and activation parameters, the cells were held at $-100 \mathrm{mV}$ and step depolarized to $+80 \mathrm{mV}$ for $200 \mathrm{~ms}$ with depolarizing $10 \mathrm{mV}$ increments. The interpulse interval was $20 \mathrm{~s}$. For neurons, a prepulse at $-10 \mathrm{mV}$ for $30 \mathrm{~ms}$ was given before each test pulse to inactivate the majority of transient-outward $\mathrm{K}^{+}$currents. For determining the steady-state inactivation parameters, the cells were held at $-100 \mathrm{mV}$ and step depolarized to $+40 \mathrm{mV}$ for $10 \mathrm{~s}$ with depolarizing $10 \mathrm{mV}$ increments (conditioning steady pulse) followed by test pulse at $+10 \mathrm{mV}$ for $400 \mathrm{~ms}$ (test pulse). The Nernst $\mathrm{K}^{+}$equilibrium potential $E_{\mathrm{K}}$ was calculated as $-84 \mathrm{mV}$. Current densities were calculated by dividing the peak current amplitude (in picoamperes) at each membrane potential with the cell capacitance (in picofarads) and plotted against the respective membrane potentials. Voltage-dependent activation and steady-state inactivation curves were generated as described previously (VanDongen et al., 1990; Mohapatra and Trimmer, 2006), and the voltage-dependent parameters are detailed in Results.

PULSE software (HEKA Electronik) was used for acquisition and analysis of currents. IGOR Pro 4 (Wavemetrics, Lake Oswego, OR), and Origin 7 software (OriginLab, Northampton, MA) were used to perform least-squares fitting and to create figures. Data are presented as mean \pm SEM or fitted value \pm SE of the fit. Paired or unpaired Student's $t$ tests (Origin) were used to evaluate the significance of changes in mean values. Values of $p<0.05$ were considered statistically significant.

\section{Results}

Coexpression of the soluble Kv2.1 cytoplasmic $\mathrm{C}$ terminus rescues the deficient cell surface expression of a tailless Kv2.1 C-terminal truncation mutant

We recently showed through transfer-of-function experiments that the cytoplasmic $\mathrm{C}$ terminus of Kv2.1 can act as an autonomous domain necessary and sufficient to transfer Kv2.1-like clustered localization and phosphorylation-dependent modulation of activation gating to chimeric Kv channels (Mohapatra and Trimmer, 2006). Each of these chimeras exhibited efficient cell surface expression (Mohapatra and Trimmer, 2006). However, previous studies had shown that "tailless" Kv2.1 truncation mutants lacking all or the last 416 aa of the 443 aa Kv2.1 C-terminal cytoplasmic tail were defective in functional expression (Bentley et al., 1999). To investigate the basis for the lack of functional expression, we generated a mutant $(\Delta \mathrm{C} 416)$ lacking the last 416 C-terminal amino acids (Fig. $1 A$, diagram) and compared its expression to wild-type Kv2.1 (Kv2.1-WT) in transfected mammalian cells, assaying surface expression levels by double immunofluorescence staining, first staining intact COS- 1 cells with an ectodomain-specific antibody, followed by permeabilization and staining with a cytoplasmically directed antibody. Although cells expressing Kv2.1-WT exhibited robust surface staining (Fig. $1 A$ ), cells expressing the $\Delta C 416$ mutant exhibited no detectable surface staining, and all detectable staining of permeabilized cells was to the perinuclear region where the RER is located (Fig. 1B). This suggests that the cytoplasmic $\mathrm{C}$ terminus of Kv2.1 is necessary for efficient export of Kv2.1 from the RER and subsequent cell surface expression, and that the lack of robust $\Delta C 416$ functional expression observed in previous studies was attributable to deficient trafficking of the tailless mutant.

Surprisingly, coexpression of the tailless $\Delta \mathrm{C} 416$ mutant with a soluble Kv2.1 fragment (2.1C) containing the bulk (amino acids 444-853) of the cytoplasmic C-terminal tail significantly increased $\Delta$ C416 surface expression (Fig. $1 D$ ). Overall, the number of cells expressing robust $\Delta \mathrm{C} 416$ surface staining increased from virtually none to $74 \%$ of the cells assayed (354 of 478 cells examined in five independent experiments). Coexpression of $\Delta \mathrm{C} 416$ with $2.1 \mathrm{C}$ also resulted in a translocation of $2.1 \mathrm{C}$ from having a diffuse cytoplasmic localization when expressed alone (Fig. 1C) to a plasma membrane-associated pattern in cells coexpressing $2.1 \mathrm{C}$ and $\Delta \mathrm{C} 416$ (Fig. $1 D$ ). The reciprocal effects of $\Delta \mathrm{C} 416$ and 2.1C coexpression on their respective subcellular localizations, and their colocalization at the plasma membrane, suggest coassembly and stable association of these two Kv2.1 fragments. Coexpression of $\Delta \mathrm{C} 416$ with the soluble $\mathrm{C}$ termini of either Kv4.3 (4.3C) (Fig. $1 F$ ) or Kv1.4 (1.4C) (supplemental Fig. S1, available at www.jneurosci.org as supplemental material) had little effect on their respective subcellular localizations. In contrast to the 


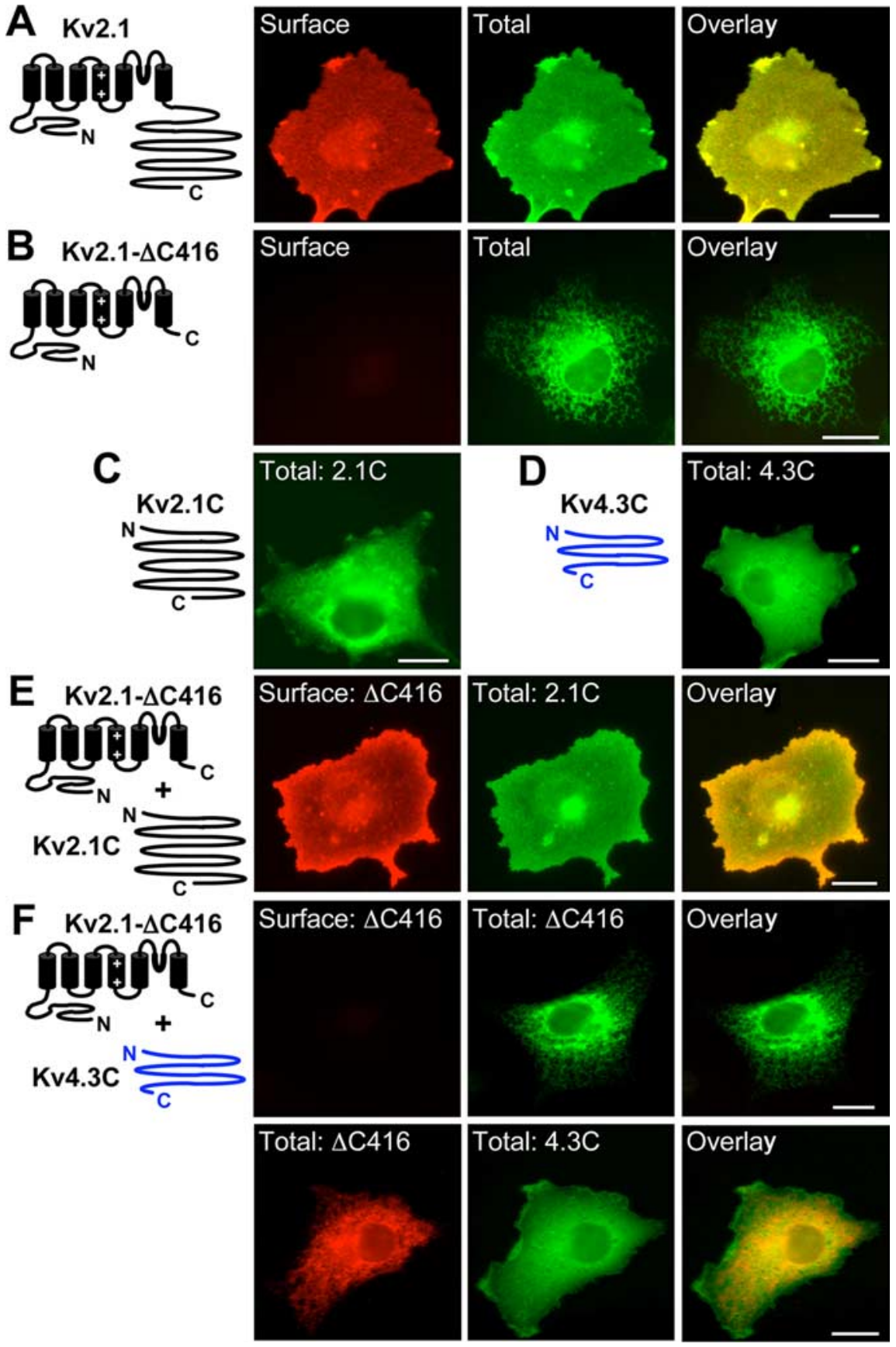
Immunofluorescence staining of Kv2.1-WT and the $\Delta$ C416 truncation mutant coexpressed without or with soluble Kv2.1C or Kv4.3C polypeptides in COS-1 cells. $\boldsymbol{A}, \boldsymbol{B}$, Surface (red) versus total (green) staining for Kv2.1-WT $(\boldsymbol{A})$ and $\Delta(416(\boldsymbol{B})$. Note no detectable surface expression of the $\Delta$ C416 truncation mutant. $C, D$, Total immunostaining (green) for the soluble $C$ terminus of Kv2.1 (2.1C; $\boldsymbol{C}$ and Kv4.3C (D) showing even distribution throughout the cytoplasm. $\boldsymbol{E}$, Surface (red) versus total (green) immunostaining of $\Delta$ C416 coexpressed with 2.1C, showing surface expression of $\Delta$ C 416 (compare with $\boldsymbol{B}$ ) colocalizing with relocalized 2.1C. $\boldsymbol{F}$, The cytoplasmic C terminus of Kv4.3 (4.3C) failed to rescue surface expression of the tailless Kv2.1 mutant. $\boldsymbol{F}$, Surface (red) versus total (green; top row) and total immunostaining (bottom row) of cells coexpressing $\Delta$ C 416 (red) and $4.3 C$ (green), showing no apparent rescue of $\Delta$ C416 surface expression and no colocalization of $\Delta$ C416 with $4.3 C$. Scale bars, $5 \mu \mathrm{m}$.
Figure 1. The soluble cytoplasmic C terminus of Kv2.1 rescues surface expression of a tailless Kv2.1 mutant in COS-1 cells.

clustered, as is Kv2.1-WT, and any chimeric Kv channel containing the Kv2.1 C terminus, expressed in HEK293 cells (Mohapatra and Trimmer, 2006). These results show that removal of the Kv2.1 C-terminal tail leads to a traffickingdeficient phenotype that can be rescued by coexpression of the soluble Kv2.1 C-terminal tail, but not the C-terminal tails of other Kv channels.

Coexpression of the soluble Kv2.1 C terminus confers Kv2.1-like voltagedependent gating properties and phosphorylation-dependent modulation to the tailless Kv2.1 mutant Although not expressing detectable cell surface immunofluorescence staining, HEK293 cells expressing $\Delta$ C416 expressed small transfection- and voltage-dependent outward currents, as determined by whole-cell voltage-clamp current recordings (Fig. $2 \mathrm{~B}, \mathrm{C}$ ). Consistent with the immunofluorescence staining, coexpression of $\Delta$ C416 with $2.1 \mathrm{C}$ led to an $\approx 11$-fold increase in the outward current density, from $63 \pm 15$ to $690 \pm 39 \mathrm{pA} / \mathrm{pF}$ (at +80 $\mathrm{mV} ; n=7 ; p<0.005$ ) (Fig. $2 B, C$ ), a level similar to that in cells expressing Kv2.1WT. The small outward currents found in HEK293 cells expressing $\Delta$ C416 had aberrant voltage-dependent gating properties, with a membrane potential for halfmaximal activation gating $\left(G_{1 / 2}\right) \approx 6 \mathrm{mV}$ shifted in the hyperpolarizing direction $\left(G_{1 / 2}=+10.5 \pm 0.2 \mathrm{mV}\right)$ relative to $\operatorname{Kv} 2.1-W T\left(G_{1 / 2}=+16.9 \pm 0.5 \mathrm{mV}\right)$, without any significant change in the voltage dependence of steady-state inactivation gating, as exhibited by similar membrane potentials for half-maximal inactivation $\left(V \mathrm{i}_{1 / 2}\right)$ (Fig. $2 D, E$; Table 1$)$. Note that the noninactivating fraction of the total $\Delta$ C416 current was increased at more positive preconditioning potentials compared with Kv2.1-WT (Fig. 2E). Coexpression of $\Delta \mathrm{C} 416$ with the soluble $2.1 \mathrm{C}$ fragment led to the restoration of WT voltage-dependent activation $\left(G_{1 / 2}=\right.$ $+19.5 \pm 0.6 \mathrm{mV})$, although the $V \mathrm{i}_{1 / 2}$ value for steady-state inactivation $(-18.3 \pm 0.4$ $\mathrm{mV}$ ) was now significantly shifted relative to Kv2.1-WT $(-27.3 \pm 0.7 \mathrm{mV}$ ) (Fig. $2 D, E$; Table 1). Moreover, coexpression of $\Delta C 416$ with $2.1 \mathrm{C}$ led to an increase in the noninactivating pool of currents at more results obtained with fragments of Kv2.1, coexpression of an intracellularly retained Kv1.4 tailless mutant (Kv1.4- $\Delta$ C84) with either its own missing $\mathrm{C}$ terminus (1.4C) or with 2.1C revealed no rescue of surface expression (supplemental Fig. S1, available at www.jneurosci.org as supplemental material).

Similar results were obtained in HEK293 cells (Fig. 2A). However, the mutants appearing on the cell surface were not positive membrane potentials compared with $\Delta \mathrm{C} 416$ (Fig. $2 E$ ).

The voltage dependence of activation and inactivation gating of Kv2.1 can be dynamically modulated by altering phosphorylation state at cytoplasmic phosphorylation sites, the bulk of which lie on the C terminus (Murakoshi et al., 1997; Mohapatra and Trimmer, 2006; Park et al., 2006). When expressed alone in HEK293 cells, $\Delta$ C416, like other C-terminal truncation mutants 
(Murakoshi et al., 1997; Mohapatra and Trimmer, 2006), exhibited a phenotype indicative of hypophosphorylation (Fig. $2 D, E$; Table 1$)$, with a left-shifted $G_{1 / 2}$ value and significantly smaller response to intracellular dialysis of AP on the voltage dependence of activation and inactivation gating $\left(\Delta G_{1 / 2}=-16.8 \mathrm{mV}\right.$ and $\Delta V \mathrm{i}_{1 / 2}=$ $-18.1 \mathrm{mV})$ than that observed for $\operatorname{Kv} 2.1-\mathrm{WT}\left(\Delta G_{1 / 2}=-36.1 \mathrm{mV}\right.$ and $\Delta V \mathrm{i}_{1 / 2}$ $=-29.2 \mathrm{mV})$. However, coexpression with $2.1 \mathrm{C}$ restored WT sensitivity of APinduced modulation of voltage-dependent activation $\left(\Delta G_{1 / 2}=-37.1 \mathrm{mV}\right)$ and inactivation $\left(\Delta V \mathrm{i}_{1 / 2}=-33.3 \mathrm{mV}\right)$ gating to $\Delta$ C416 (Fig. $2 D, E$; Table 1). These studies show that coexpression of the soluble C-terminal tail restores WT cell surface expression, voltage-dependent gating and phosphorylation-dependent modulation to tailless mutants.

We extended these studies in heterologous cells by performing parallel studies in primary CHNs. We transfected $\mathrm{CHNs}$ with HA epitope-tagged Kv2.1-WT, or HA-tagged $\Delta$ C416 (HA- $\Delta$ C416), with or without coexpression of myc epitopetagged 2.1C (2.1C-myc). We then performed immunocytochemical and wholecell voltage-clamp electrophysiological analyses as for heterologous cells above. Before these $\mathrm{CHN}$ experiments, we verified that the epitope-tagged HA- $\Delta$ C416 and 2.1C-myc exhibited characteristics identical with the respective untagged constructs when expressed singly or together in COS-1 cells (data not shown). As previously shown (Lim et al., 2000), WT HAKv2.1 expressed in CHNs exhibited efficient cell surface expression and was clustered on the soma and proximal dendrites (Fig. $3 A$ ). HA- $\Delta$ C416 expressed in $\mathrm{CHNs}$ had a perinuclear, RER-like localization, and 2.1C-myc was diffuse and cytoplasmic (Fig. 3A), consistent with their respective localizations in COS-1 and HEK293 cells (Figs. 1, 2). Coexpression of 2.1C-myc rescued HA- $\Delta$ C416 surface expression in neurons, as determined by staining of intact CHNs with an ectodomain-directed anti-Kv2.1 antibody (Fig. 3A). Interestingly, as with HEK293 cells, the surface expressed HA- $\Delta$ C416 was not clustered, and also did not exhibit the restricted subcellular localization on proximal dendrites, as did Kv2.1-WT (Fig. 3A), but was now found in the full extent of the dendrites.

Expression of HA- $\Delta$ C416 alone in $\mathrm{CHNs}$ yielded a significant decrease in the amplitude of whole-cell delayed rectifiertype Kv current, the majority of which are contributed by Kv2.1 channels (Murako-

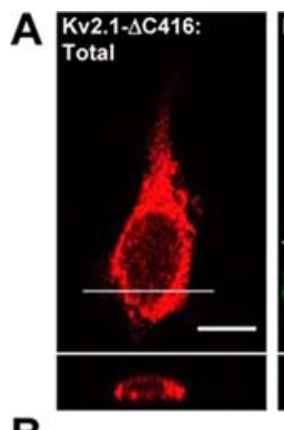

B
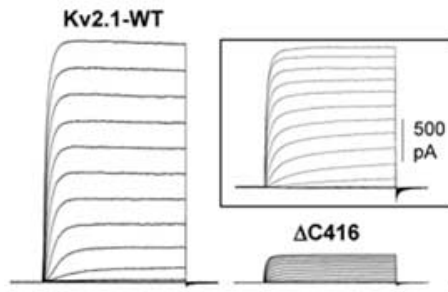

$\Delta C 416+2.1 C$
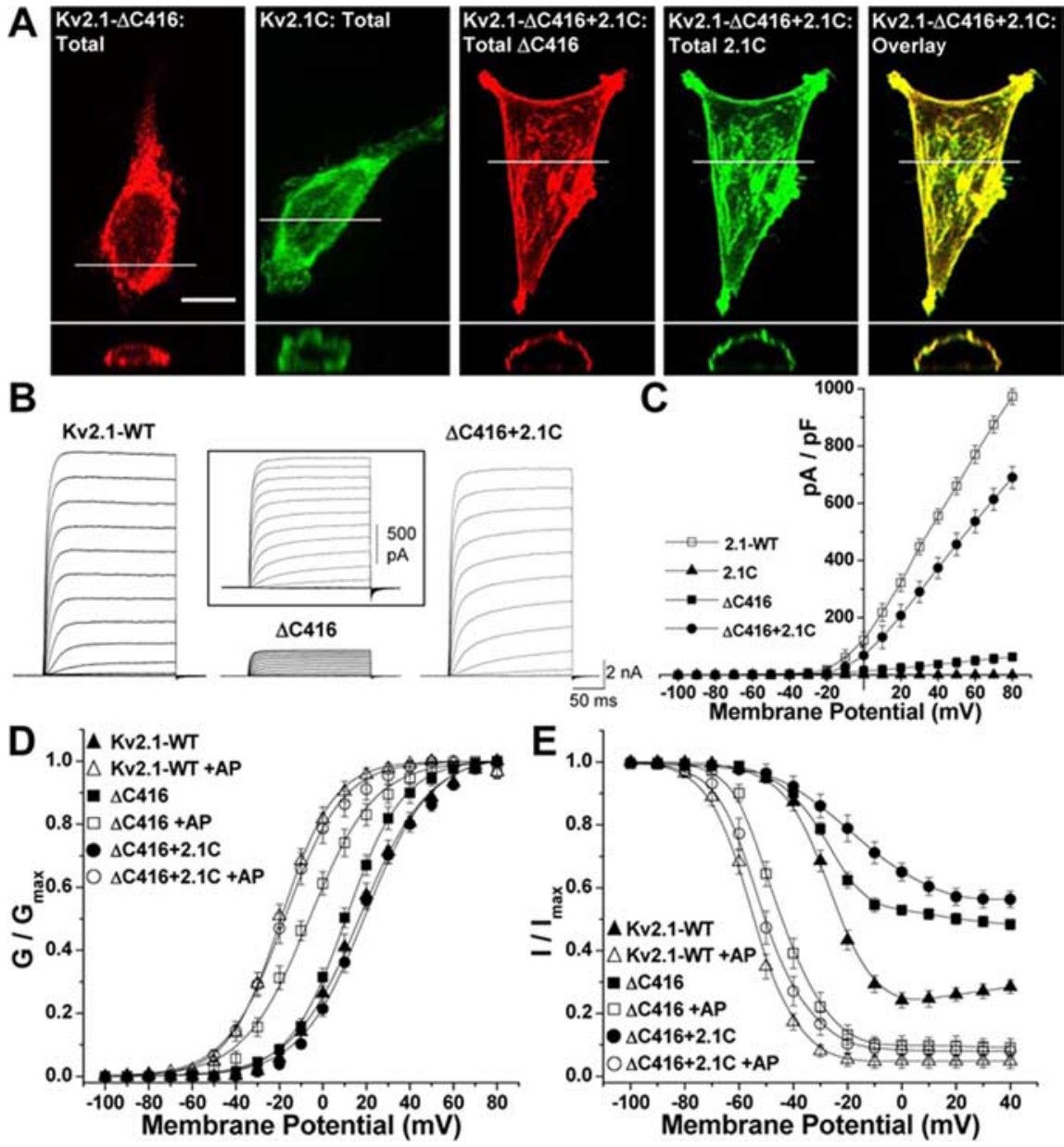

Figure 2. Coexpression of Kv2.1- $\Delta$ C416 and 2.1C in HEK293 cells enhances surface expression of functional channels and restoration of WT voltage-dependent gating properties. $\boldsymbol{A}$, Immunostaining for $\Delta C 416$ (red) and $2.1 C$ (green) in HEK293 cells. The images (top) are extended focus images of 40 cross-sectional $X-Z$ sections $(0.35 \mu \mathrm{m})$ through the cell. The bottom panel below each cell is the cross-sectional view at the level of drawn line. Note the redistribution of both $\Delta C 416$ and $2.1 C$, which are now colocalized on the cell surface when coexpressed, as opposed to perinuclear and scattered cytoplasmic localization of $\Delta$ (416 and 2.1C, respectively, when expressed alone. Scale bar, $5 \mu \mathrm{m}$. B B Representative whole-cell current traces obtained from HEK293 cells of comparable cell capacitance, transfected with either Kv2.1-WT, $\Delta(416$, or $\Delta$ C 416 plus 2.1C (1:1). The cells were held at -100 $\mathrm{mV}$ and depolarized for $200 \mathrm{~ms}$ to $+80 \mathrm{mV}$ in $10 \mathrm{mV}$ increments. Inset, Magnified $\Delta$ C416 current. C, Current density plot of whole-cell current recordings of 2.1-WT or mutant constructs (as in $\boldsymbol{B}$ ). Data are presented as mean picoamperes per picofarad \pm SEM ( $n=7$ each). $\boldsymbol{D}, \boldsymbol{E}$, Coexpression of $\Delta$ ( 416 with $2.1 \mathrm{C}$ in HEK293 cells leads to the restoration of WT voltage-dependent activation gating $(\boldsymbol{D})$ but yields a further shift in steady-state inactivation gating $(\boldsymbol{E})$ properties. Intracellular dialysis of AP (100 $\mathrm{U} / \mathrm{ml}$ ) led to similar magnitude of hyperpolarizing shifts in the half-maximal conductance $\left(G_{1 / 2}\right)$ and half-maximal steady-state inactivation $\left(\mathrm{Vi}_{1 / 2}\right)$ properties of reconstituted ( $\Delta$ C416 plus $2.1 \mathrm{C}$ ) channels and WT-Kv2.1, but not $\Delta$ C416. Voltage-dependent activation $(\boldsymbol{D})$ and steady-state inactivation $(\boldsymbol{E})$ curves were generated as described in Materials and Methods, and the voltagedependent parameters are detailed in Table 1.

Table 1. Voltage-dependent gating properties of Kv2.1-WT and truncation constructs expressed either alone or coexpressed in HEK293 cells without or with intracellular dialysis of AP (100 U/ml for $30 \mathrm{~min}$ )

\begin{tabular}{|c|c|c|c|c|c|}
\hline \multirow[b]{2}{*}{ Kv2.1 constructs } & \multicolumn{2}{|c|}{ Voltage-dependent activation } & \multicolumn{2}{|c|}{ Steady-state inactivation } & \multirow[b]{2}{*}{$n$} \\
\hline & $G_{1 / 2}(\mathrm{mV})$ & $k$ & $\mathrm{Vi}_{1 / 2}(\mathrm{mV})$ & $k$ & \\
\hline Kv2.1-WT & $+16.9 \pm 0.5$ & $15.4 \pm 0.6$ & $-27.3 \pm 0.7$ & $7.9 \pm 0.6$ & 7 \\
\hline Kv2.1-WT + AP & $-19.2 \pm 0.4$ & $12.1 \pm 0.4$ & $-57.2 \pm 0.4$ & $7.4 \pm 0.3$ & 5 \\
\hline Kv2.1- $\Delta$ C416 & $+10.5 \pm 0.2^{*}$ & $13.0 \pm 0.3$ & $-27.6 \pm 0.6$ & $9.3 \pm 0.6$ & 7 \\
\hline $\mathrm{Kv} 2.1-\Delta \mathrm{C} 416+\mathrm{AP}$ & $-6.3 \pm 0.5^{*}$ & $15.1 \pm 0.5$ & $-45.7 \pm 0.3^{*}$ & $7.8 \pm 0.3$ & 6 \\
\hline $\mathrm{Kv} 2.1-\Delta \mathrm{C} 416+\mathrm{Kv} 2.1 \mathrm{C}$ & $+19.5 \pm 0.6$ & $14.8 \pm 0.5$ & $-18.3 \pm 0.4^{*}$ & $14.4 \pm 0.3^{*}$ & 7 \\
\hline Kv2.1- $\Delta C 416+K v 2.1 C+A P$ & $-17.6 \pm 0.5$ & $13.4 \pm 0.5$ & $-51.6 \pm 0.3^{*}$ & $8.0 \pm 0.5$ & 4 \\
\hline
\end{tabular}

$\mathrm{G}_{1 / 2}$ is the half-maximal voltage dependence of channel activation. $\mathrm{Vi}_{1 / 2}$ is the half-maximal voltage dependence of steady-state inactivation of channels. $k$ is the slope factor of the activation or inactivation curve.

*Significantly different in comparison with respective Kv2.1-WT values without or with AP. 


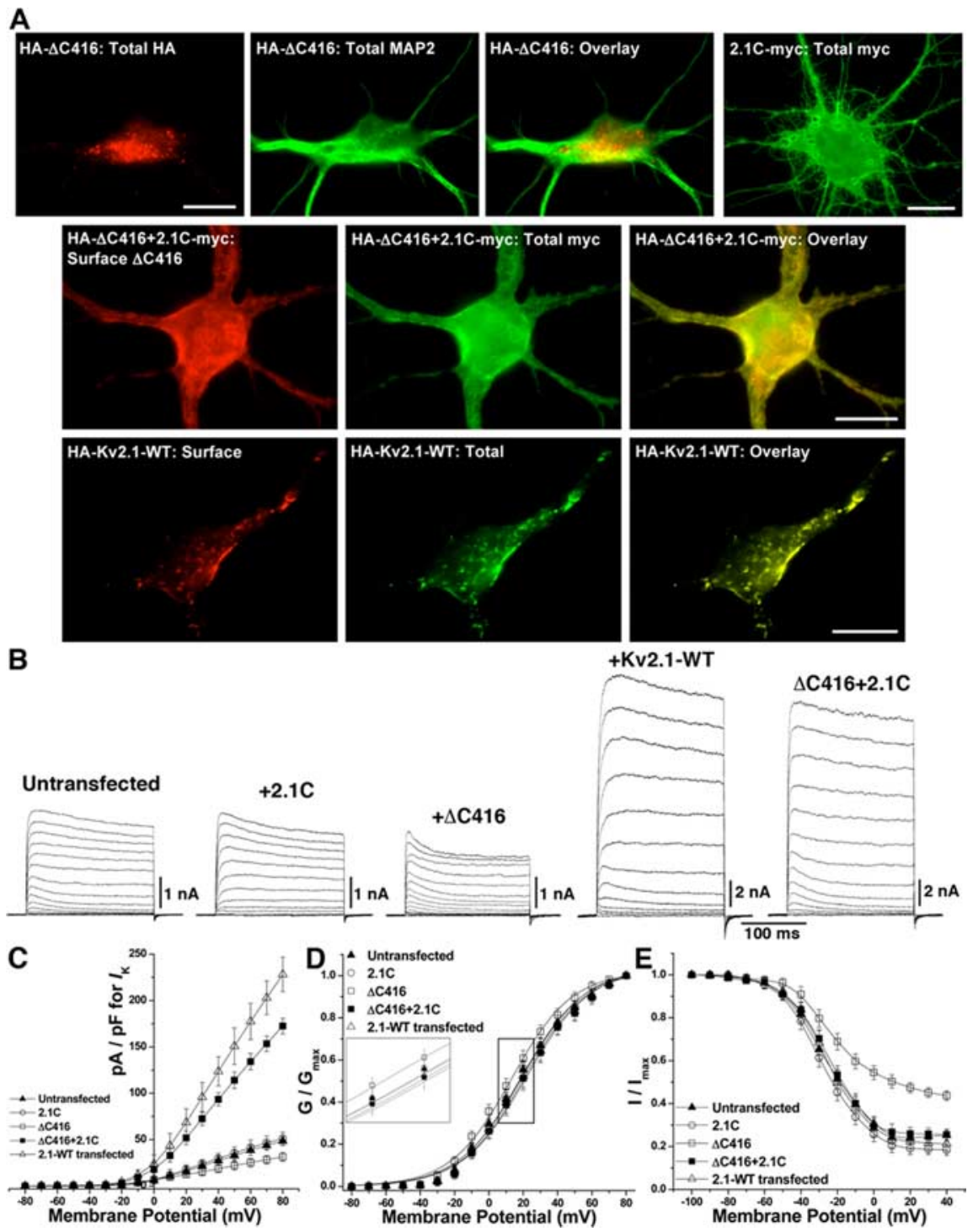

Figure 3. The soluble 2.1C fragment rescues the surface expression and voltage-dependent gating properties of delayed rectifier Kv currents from the tailless mutant in cultured rat hippocampal neurons. $\boldsymbol{A}$, Immunofluorescence staining of transfected neurons. Top row, Neurons expressing either HA- $\Delta$ C416 or 2.1C-myc alone showing total staining for HA- $\Delta$ C 416 (red) and the dendritic marker MAP2 (green) or 2.1C-myc (green), as indicated. Middle row, Neurons cotransfected with HA- $\Delta$ C416 and 2.1C-myc showing HA- $\Delta$ C416 surface staining (red) and 2.1C-myc total staining (green). Note the redistribution of HA- $\Delta$ C416 when coexpressed with 2.1C-myc. Bottom row, Neurons transfected with HA-Kv2.1-WT showing surface (red) and total (green) staining. Scale bars, $10 \mu \mathrm{m} . \boldsymbol{B}$, Representative whole-cell $I_{\mathrm{K}}$ current recordings from neurons without or with the transfection of the above-mentioned Kv2.1 constructs as per the voltage-pulse protocol described in Materials and Methods. C, Current density plot of whole-cell $I_{\mathrm{K}}$ current recordings from the transfected or untransfected neurons as mentioned in $\boldsymbol{B}$. Data are presented as mean picoamperes/picofarad \pm SEM ( $n=4$ each). $\boldsymbol{D}, \boldsymbol{E}$, Coexpression of HA- $\Delta$ C416 and 2.1C-myc leads to the restoration of WT voltage-dependent activation gating $(\boldsymbol{D})$ and steady-state inactivation gating $(\boldsymbol{E})$ properties of neuronal $I_{\mathrm{K}}$ currents. A magnified view of the area marked with a rectangle on the $G-V$ relationship curve is shown as an inset in $\boldsymbol{D}$. The voltage-dependent activation and steady-state inactivation curves for $I_{K}$ were generated as detailed in Materials and Methods, and the voltagedependent parameters are detailed in Table 2.

shi and Trimmer, 1999), compared with 2.1C-myc-transfected or untransfected CHNs (Fig. $3 B, C$ ). This result presumably reflects negative effects of coassembly with trafficking deficient HA$\Delta \mathrm{C} 416$ subunits on the trafficking of endogenous Kv2.1 subunits. In contrast, coexpression of HA- $\Delta \mathrm{C} 416$ with 2.1C-myc in $\mathrm{CHNs}$ led to significant increase in the density of whole-cell delayed rectifier-type currents relative to untransfected CHNs (Fig. $3 B, C)$, and this additional current, presumably caused by the 2.1C-dependent increase in surface expression of $\Delta C 416$, exhibited voltage-dependent gating properties typical of Kv2.1-WT
(Fig. 3C,D). These results show that, in CHNs, the separate Kv2.1 C terminus can rescue the intracellular trafficking and functional surface expression, but not clustering, of the C-terminally truncated tailless $\Delta \mathrm{C} 416$ mutant.

The cytoplasmic C terminus of Kv2.1 physically interacts with the Kv2.1 cytoplasmic $\mathrm{N}$ terminus

The results above, showing that coexpression of the soluble $2.1 \mathrm{C}$ fragment rescues $\Delta \mathrm{C} 416$ surface expression and leads to reciprocal changes in their respective subcellular localizations, suggest a direct physical interaction between these two channel fragments. We directly investigated this by reciprocal co-IP experiments performed on HEK293 cell lysates. $\Delta$ C416 from $\Delta \mathrm{C} 416 / 2.1 \mathrm{C}$ coexpressing cells was present in co-IP reactions performed with an antibody specific for 2.1C (Fig. 4A), and vice versa (Fig. $4 B$ ). $\Delta$ C416 was not present in IP reactions performed with anti-2.1C antibody, nor $2.1 \mathrm{C}$ with anti$\Delta \mathrm{C} 416$ antibody. Digestion of extracts from $\Delta \mathrm{C} 416 / 2.1 \mathrm{C}$ coexpressing cells with AP did not disrupt this interaction (supplemental Fig. S2, available at www. jneurosci.org as supplemental material), although it did alter the mobility of $2.1 \mathrm{C}$ on SDS gels, suggesting effective dephosphorylation of the fragment containing the bulk of Kv2.1 phosphorylation sites. This suggests that, once established, the interaction between $\Delta \mathrm{C} 416$ and $2.1 \mathrm{C}$ is not dependent on phosphorylation per se.

We next used co-IP to examine the regions of $\Delta \mathrm{C} 416$ that were necessary for its interaction with $2.1 \mathrm{C}$. The major cytoplasmic regions remaining in $\Delta \mathrm{C} 416$ are the linker between transmembrane segments $\mathrm{S} 4$ and S5 (S4-S5 linker) and the extended N terminus. To determine whether the Kv2.1 S4-S5 linker was required for the interaction, we generated a chimera $(\Delta \mathrm{C} 416-\mathrm{Chi})$ wherein the 14 aa residue S4-S5 linker of $\Delta \mathrm{C} 416$ was substituted with the distinct S4-S5 linker (10/16 aa residues identical) from Kv1.2. There was no discernible difference between $\Delta C 416$-Chi and $\Delta C 416$ in the interaction with $2.1 \mathrm{C}$ in the co-IP assay (Fig. $4 C)$.

Initial experiments showed that $2.1 \mathrm{C}$ did not interact with $\Delta$ C416 lacking the bulk (the first 139 of 180 aa) of the $\mathrm{N}$ terminus ( $\Delta$ N139- $\Delta$ C416) (data not shown), indicating that the $\mathrm{N}$ terminus of Kv2.1 was necessary for this interaction. Moreover, coexpression with $2.1 \mathrm{C}$ did not rescue trafficking of the $\Delta$ N139$\Delta$ C416 mutant that lacks both the $\mathrm{N}$ - and C-terminal cytoplasmic domains. That the $\mathrm{N}$ terminus of Kv2.1 was sufficient for $2.1 \mathrm{C}$ interaction was shown by co-IP of the soluble cytoplasmic N terminus of Kv2.1 (2.1N; aa 1-180) with $2.1 \mathrm{C}$ from coexpressing HEK293 cells (Fig. 4C). Moreover, we found 
that the interactions between the cytoplasmic $\mathrm{N}$ and $\mathrm{C}$ terminus of Kv2.1 appear to underlie the rescue of efficient $\Delta C 416$ surface expression by $2.1 \mathrm{C}$. COS- 1 cells expressing constant amounts of $\Delta \mathrm{C} 416$ and 2.1C were cotransfected with increasing amounts of the soluble $2.1 \mathrm{~N}$ fragment. Importantly, expression of increasing amounts of $2.1 \mathrm{~N}$ yielded a dosedependent inhibition of the 2.1Cmediated rescue of $\Delta C 416$ cell surface expression, suggesting that the soluble Kv2.1 $\mathrm{N}$ terminus could compete with the $\mathrm{N}$ terminus of $\Delta \mathrm{C} 416$ for binding to $2.1 \mathrm{C}$ (supplemental Fig. S3, available at www.jneurosci.org as supplemental material). Expression of comparable amounts of the Kv1.4 N terminus had no effect (supplemental Fig. S3, available at www.jneurosci.org as supplemental material). These results suggest that the specific interaction between the cytoplasmic $\mathrm{N}$ and $\mathrm{C}$ termini of Kv2.1 is critical to efficient Kv2.1 cell surface expression.

We next analyzed the physical interaction of $\Delta \mathrm{C} 416,2.1 \mathrm{C}$, and $2.1 \mathrm{~N}$ by sucrose density gradient centrifugation analyses of Triton X-100 extracts of singly expressing or coexpressing HEK293 cells. Representative results from one of three independent experiments are shown in Figure $4 D$. Wild-type Kv2.1 migrated as a fairly tight peak in fractions $4-6$ of the gradient (Fig. $4 D$ ), presumably representing a homogeneous population of correctly assembled Kv2.1 tetramers. $\Delta$ C416 exhibited a similar peak, although now present in lighter fractions 3-5, presumably representing tetramers of the smaller truncation mutant (Fig. 4D). However, $\Delta \mathrm{C} 416$ species were also spread throughout lighter and heavier fractions, suggesting heterogeneity in the oligomeric state of the mutant that was not observed for Kv2.1-WT (Fig. 4D). 2.1C was found in the lightest gradient fractions, with a peak in the fraction 1 , presumably representing unassembled $2.1 \mathrm{C}$ as the overall mass of this cytoplasmic fragment is similar to that of $\Delta C 416$ (both $\approx 400-450 \mathrm{aa})$. Interestingly, coexpression of $\Delta \mathrm{C} 416$ and $2.1 \mathrm{C}$ led to a slight change in the mobility of $\Delta C 416$ to a peak similar to that of Kv2.1-WT (fractions 4-6), although some heterogeneity not seen for Kv2.1-WT persisted. When coexpressed with $\Delta \mathrm{C} 416$, the mobility of $2.1 \mathrm{C}$ changed dramatically, such that it now comigrated with $\Delta \mathrm{C} 416$ at its altered position near Kv2.1-WT. This suggests that $\Delta \mathrm{C} 416$ and 2.1C form a stable complex that reconstitutes the hydrodynamic properties of Kv2.1-WT.

The cytoplasmic $2.1 \mathrm{~N}$ fragment when expressed alone migrated throughout the heavier gradient fractions (fraction 3 and higher). That $2.1 \mathrm{~N}$ is small (180 aa) relative to $2.1 \mathrm{C}$ (414 aa) yet migrates in heavier fractions on these gradients suggests that this

\section{$2.1 \mathrm{~N}+2.1 \mathrm{C}$ : IB - 2.1C \\ 2.1N+2.1C: IB $-2.1 \mathrm{~N}$}

Table 2. Voltage-dependent gating properties of $I_{K}$ currents of untransfected or transfected cultured rat hippocampal neurons with HA-Kv2.1-WT, HA-Kv2.1- $\Delta$ C416, and Kv2.1C-myc alone or in combination

\begin{tabular}{|c|c|c|c|c|c|}
\hline \multirow[b]{2}{*}{ Transfected Kv2.1 constructs } & \multicolumn{2}{|c|}{ Voltage-dependent activation } & \multicolumn{2}{|c|}{ Steady-state inactivation } & \multirow[b]{2}{*}{$n$} \\
\hline & $G_{1 / 2}(\mathrm{mV})$ & $k$ & $V \mathrm{i}_{1 / 2}(\mathrm{mV})$ & $k$ & \\
\hline Untransfected & $+17.1 \pm 0.7$ & $16.3 \pm 0.6$ & $-26.8 \pm 0.5$ & $11.6 \pm 0.4$ & 4 \\
\hline HA-Kv2.1-WT & $+18.3 \pm 0.9$ & $16.5 \pm 0.5$ & $-26.3 \pm 0.6$ & $11.1 \pm 0.7$ & 4 \\
\hline $\mathrm{HA}-\Delta \mathrm{C} 416$ & $+12.1 \pm 0.6$ & $15.7 \pm 0.5$ & $-20.7 \pm 0.7$ & $13.5 \pm 0.6$ & 4 \\
\hline 2.1c-myc & $+17.3 \pm 0.8$ & $16.4 \pm 0.7$ & $-28.0 \pm 0.3$ & $11.2 \pm 0.3$ & 4 \\
\hline$H A-\Delta C 416+2.1 c-m y c$ & $+19.2 \pm 0.8$ & $16.5 \pm 0.7$ & $-25.6 \pm 0.4$ & $11.4 \pm 0.4$ & 4 \\
\hline
\end{tabular}

$G_{1 / 2}$ is the half-maximal voltage-dependence of channel activation. $V_{i_{1 / 2}}$ is the half-maximal voltage dependence of steady-state inactivation of channels. $k$ is the slope factor of the activation or inactivation curve.

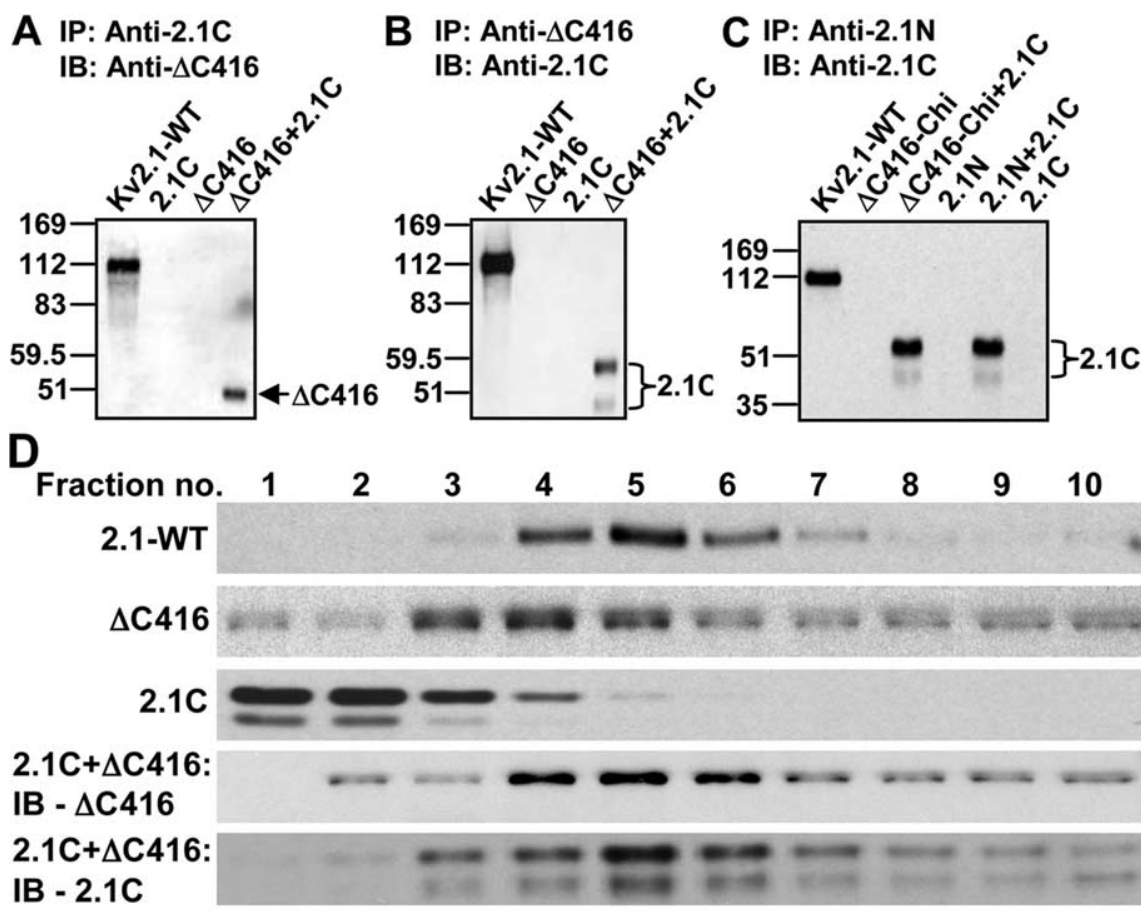

Figure 4. The cytoplasmic $\mathrm{N}$ terminus of the Kv2.1- $\Delta$ C 416 truncation mutant interacts directly with 2.1C. $A, B, C 0-\mathrm{IP}$ of $2.1 \mathrm{C}$ and $\Delta$ C416 from HEK293 cells cotransfected with $\Delta C 416$ and 2.1C (at 1:1 ratio), using KC (recognizing Kv2.1-WT and 2.1C but not $\Delta$ C416) (A) or Kv2.1e (recognizing Kv2.1-WT and $\Delta$ C416 but not 2.1C) (B).C, Co-IP of 2.1C with $\Delta$ C416-Chimera (S4-S5 linker of Kv2.1 replaced with that of Kv1.2) or 2.1N from HEK293 cells expressing either construct alone or together (at 1:1 ratio), using anti-Kv2.1N antibody (recognizing Kv2.1-WT, $\Delta$ (416-Chimera, and 2.1N but not 2.1C). Immunoprecipitation products were size-fractionated by $7.5 \%(\boldsymbol{A}, \boldsymbol{B})$ or $9 \%$ (C) SDS-PAGE and analyzed by immunoblot/ECL with $\mathrm{mAbs}$ K39/25 (recognizing Kv2.1-WT and $\Delta(416$ but not 2.1C) $(\boldsymbol{A})$ or K89/41 (recognizing Kv2.1-WT and 2.1C but not 2.1 $\mathrm{N}$ and $\Delta(416)(\boldsymbol{B}, \boldsymbol{C})$. Numbers to the left of each panel refer to mobility of prestained molecular weight standards in kilodaltons. $\boldsymbol{D}$, Representative nondenaturing sucrose density gradient sedimentation patterns of Kv2.1-WT and mutant constructs expressed in HEK293 cells, as indicated.

T1 domain-containing fragment assembles into tetramers and higher order oligomers. It is also possible that $2.1 \mathrm{~N}$ interacts with other cellular proteins to form these larger complexes. Coexpression of $2.1 \mathrm{~N}$ with $2.1 \mathrm{C}$ led a change in the mobility of both fragments such that they now comigrated with a peak in fraction 2, with a dramatic loss of the heterogeneity seen in cells expressing $2.1 \mathrm{~N}$ alone. These assays provide strong biochemical support for physical interaction between $\Delta \mathrm{C} 416$ and $2.1 \mathrm{C}$, and $2.1 \mathrm{~N}$ and $2.1 \mathrm{C}$, and suggest the formation of distinct molecular species comprising the coexpressed fragments. 


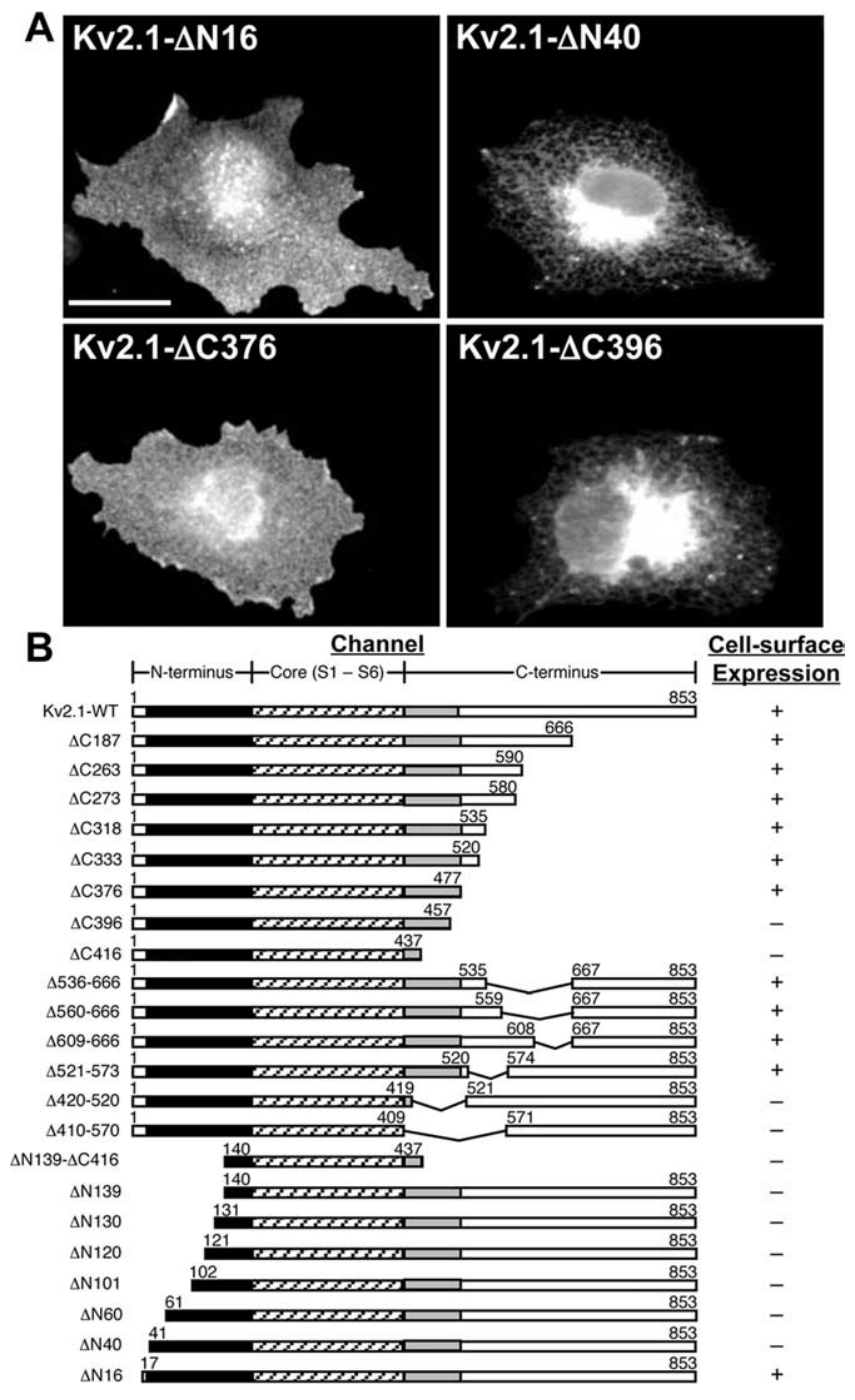

Figure 5. Truncation analyses of determinants of Kv2.1 cell surface expression. $\boldsymbol{A}$, Total immunofluorescence staining for $\Delta N 16, \Delta N 40, \Delta C 376$, and $\Delta C 396$ truncation mutants of Kv2.1 expressed in HEK293 cells, showing plasma membrane-associated localization of $\Delta \mathrm{N} 16$ and $\Delta C 376$ mutants and RER-like localization of $\Delta N 40$ and $\Delta C 396$ mutants. Scale bar, $10 \mu \mathrm{m}$. $B$, Schematic diagram of the Kv2.1 C- and N-terminal truncation and internal deletion mutants used to define the minimal motifs required for efficient plasma membrane localization. In the right column, $(+)$ indicates efficient cell surface localization, whereas $(-)$ indicates no detectable surface expression, as determined by surface and total immunofluorescence staining assay.

\section{Identification of segments within the Kv2.1 $\mathrm{N}$ and $\mathrm{C}$ termini} that mediate their interaction and regulate Kv2.1 surface expression

To identify the regions of the Kv2.1 N and C termini necessary for mediating their interaction, we first determined the minimal regions in the cytoplasmic domain necessary for efficient Kv2.1 surface expression. We analyzed a series of serial truncation and internal deletion mutants in the cytoplasmic $\mathrm{C}$ and $\mathrm{N}$ termini of Kv2.1 for surface expression efficiency (Fig. 5A). Serial truncation mutants of the Kv2.1 C terminus up to amino acid 477 (e.g., $\Delta \mathrm{C} 376)$ yielded mutants that were not obviously different from Kv2.1-WT (Fig. 5A,B). However, additional truncation (e.g., $\Delta \mathrm{C} 396$ ) yielded a phenotype similar to $\Delta C 416$, with no detectable cell surface staining and an RER-like localization (Fig. 5A,B). These data suggest that a 67 aa segment in the proximal $C$ terminus of Kv2.1 (amino acids 411-477) is necessary for efficient cell surface expression of Kv2.1. Internal deletion mutants disrupting

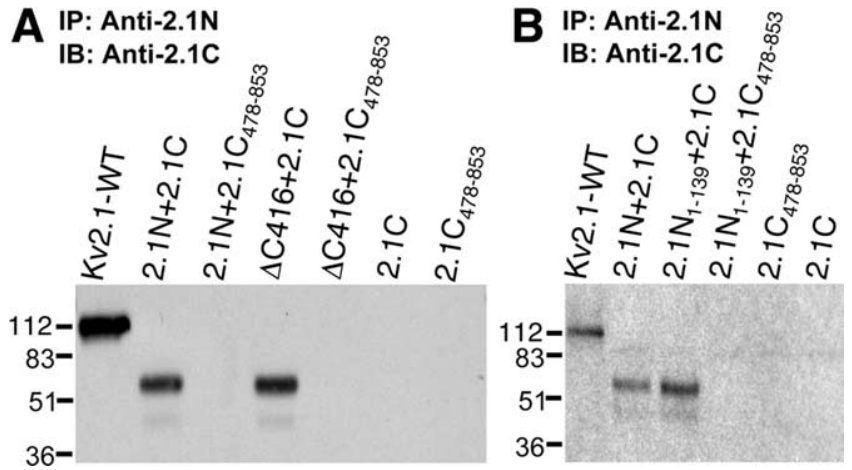

Figure 6. The proximal 67 aa residues in the cytoplasmic $\mathrm{C}$ terminus are essential for direct interaction of 2.1C with Kv2.1 N terminus. A, Lysates from HEK293 cells expressing Kv2.1-WT or $2.1 \mathrm{~N}$, soluble $2.1 \mathrm{C}$, and $2.1 \mathrm{C}$ lacking the first 67 aa residues $\left(2.1 C_{478-853}\right)$, either alone or in combination, were subjected to immunoprecipitation with the Kv2.1N antibody (recognizes Kv2.1-WT, $\Delta$ (416, and 2.1N but not 2.1C). Immunoprecipitation products were sizefractionated by 9\% SDS-PAGE and analyzed by immunoblot/ECL using the mAb K89/41 (recognizes Kv2.1-WT, 2.1C, and 2.1 $C_{478-853}$ but not $\Delta(416$ and 2.1N). Note that $\Delta(416$ and 2.1N interact with 2.1C but not 2.1 $C_{478-853} \cdot B, 2.1$ interacts with the cytoplasmic $\mathrm{N}$ terminus of the channel protein comprising the full-length tetramerization (T1) domain. Lysates from HEK293 cells expressing Kv2.1-WT or 2.1N, 2.1N $\mathrm{N}_{1-139}, 2.1 \mathrm{C}$, and 2.1C $\mathrm{C}_{478-853}$, either alone or in combination, were subjected to immunoprecipitation with Kv2.1N antibody (recognizes Kv2.1-WT, 2.1N, and 2.1 $\mathrm{N}_{1-139}$ but not 2.1C). Immunoprecipitation products were size-fractionated by $9 \%$ SDS-PAGE and analyzed by immunoblot/ECL using mouse mAb K89/41 that recognizes Kv2.1WT, 2.1C and 2.1C $478-853$ but not $2.1 \mathrm{~N}$ or $2.1 \mathrm{~N}_{1-139}$. Numbers to the left of each panel refer to mobility of molecular weight standards in kilodaltons.

this segment also disrupted efficient Kv2.1 cell surface expression (Fig. 5B). Note that a recent report has suggested that internal deletion of amino acids 411-523 still yields functional expression of the mutant in PC12 cells (Singer-Lahat et al., 2007). However, PC12 cells express endogenous Kv2.1 (Sharma et al., 1993), such that it is possible that coassembly of endogenous Kv2.1 with the $\Delta 411-523$ mutant allows for functional expression of the latter. The basis for the functional expression of the $\Delta 411-523$ mutant in PC12 cells, but not in HEK or COS, warrants additional investigation. We next tested whether this segment mediated the physical interaction of $2.1 \mathrm{C}$ with $\Delta \mathrm{C} 416$ and $2.1 \mathrm{~N}$. We generated a 2.1C mutant starting at amino acid 478 instead of 444, termed $2.1 \mathrm{C}_{478-853}$. Co-IP experiments revealed that neither $\Delta \mathrm{C} 416$ nor $2.1 \mathrm{~N}$ was able to associate with $2.1 \mathrm{C}_{478-853}$ (Fig. 6A). The $2.1 \mathrm{C}_{478-853}$ mutant was also unable to rescue the cell surface expression of $\Delta C 416$ (data not shown). We conclude from these experiments that the 34 -aa-long segment $(444-477)$ that distinguishes $2.1 \mathrm{C}$ from $2.1 \mathrm{C}_{478-853}$ constitutes the motif that interacts with the Kv2.1 cytoplasmic $\mathrm{N}$ terminus.

Serial truncation of the cytoplasmic N terminus of Kv2.1 showed that the majority of the cytoplasmic N-terminal region, except for the first 16 aa residues, is required for efficient Kv2.1 cell surface expression (Fig. 5A,B). However, the $\mathrm{N}$ terminus contains the T1 domain (amino acids 27-133) that mediates efficient tetramerization, also required for efficient surface expression of Kv channels (Papazian, 1999). To avoid this complication, we used co-IP to directly test the region(s) in the cytoplasmic $\mathrm{N}$ terminus of $\mathrm{Kv} 2.1$ critical for interaction with the $\mathrm{C}$ terminus. We generated fragments of $2.1 \mathrm{~N}$ consisting of the T1 domain $\left(2.1 \mathrm{~N}_{1-}\right.$ 139), and found that this shorter fragment, like the original $2.1 \mathrm{~N}$ (amino acids 1-180) was in a co-IP complex with 2.1C but not 2.1C $478-853$ (Fig. 6B).

To gain additional insights into the binding site for $2.1 \mathrm{C}$ on the Kv2.1 $\mathrm{N}$ terminus, we used homology modeling to generate a structure of the Kv2.1 T1 domain based on the known crystal 
structures of the T1 domains of other $\mathrm{Kv}$ channels. Based on sequence alignment, percentage amino acid similarity, and conserved $\mathrm{Zn}^{2+}$-binding motif, a model was generated with SWISS-MODEL (Guex and Peitsch, 1997; Schwede et al., 2003) using the Kv3.1 T1 domain crystal structure as the template. A comparative view of the T1 domain structures of Kv1.2 (Minor et al., 2000), Kv3.1 (Bixby et al., 1999), Kv4.2 (Nanao et al., 2003), and Kv2.1 T1 domains is given in Figure $7 B$. Such homology modeling showed the existence of a distinct loop (residues 55-71) near the bottom of the Kv2.1 T1 domain that was the only remarkable structural difference in Kv2.1 compared with Kv1.2, Kv3.1 and Kv4.2 (Fig. 7B). Deletion of the 17 aa residues (55-71) comprising this loop yielded an internal deletion mutant (Kv2.1 $\Delta 55$ 71) that is not expressed on the cell surface and exhibits an RER-like localization (Fig. 7C). To determine whether the effects of this deletion were attributable to a lack of assembly, we compared Kv2.1 $\Delta 55-71$ to Kv2.1-WT on sucrose density gradients. Kv2.1 $155-71$ comigrated with Kv2.1-WT on these gradients, with a peak in fractions 5 , whereas heat-denatured Kv2.1 in the presence of reducing agent $(\beta$ mercaptoethanol) migrated in lighter fractions with a peak in fractions 3, presumably representing monomeric Kv2.1 (Fig. $7 D)$. These data suggest that, although cell surface expression of Kv2.1 $\Delta 55-71$ is deficient, the tetramerization of this mutant is intact. We next directly tested whether the Kv2.1 N terminus lacking this segment could still interact with 2.1C. A soluble Kv2.1N lacking amino acid residues 55-71 termed " $2.1 \mathrm{~N}-\Delta 55-71$," unlike $2.1 \mathrm{~N}$, could not associate with 2.1C (Fig. 7E), strongly suggesting that this Kv2-specific T1 domain motif physically interacts with the proximal cytoplasmic $\mathrm{C}$ terminus to mediate N/C interaction and regulate Kv2.1 trafficking and voltage-dependent channel gating.

We next tested whether $\mathrm{N} / \mathrm{C}$ interaction is required for phosphorylation-dependent modulation of Kv2.1 gating. We first determined whether deletion of the C-terminal interaction motif in the Kv2.1 N terminus affects the phosphorylation state of the mutant. Digestion of Kv2.1- $\Delta 55-71$ expressing HEK293 cell lysates with AP led to enhanced electrophoretic mobility of the mutant that was similar to that observed for Kv2.1-WT (Fig. 8 A), indicative of similar overall levels of constitutive phosphorylation of the two channels. Moreover, immunoblots of these lysates probed with phosphospecific anti-Kv2.1 antibodies generated against four major phosphorylation sites (pS453, pS563, pS603, and pS715) showed that the Kv2.1- $\Delta 55-71$ mutant is constitutively phosphorylated at each these sites, which are dephosphorylated on AP treatment (Fig. $8 \mathrm{~A}$ ). Whole-cell patch-clamp recordings from HEK293 cells transiently expressing the Kv2.1$\Delta 55-71$ mutant showed an $\approx 15$-fold decrease in the outward current density compared with Kv2.1-WT (Fig. 8B). The Kv2.1$\Delta 55-71$ mutant had voltage-dependent activation gating proper- ties resembling partially dephosphorylated Kv2.1, and the $\Delta C 416$ tailless mutant (Fig. $2 D$ ) with $G_{1 / 2}$ value shifted $\approx 21 \mathrm{mV}$ in the hyperpolarizing direction $\left(G_{1 / 2}=-3.8 \pm 0.7 \mathrm{mV} ; n=5\right)$ relative to Kv2.1-WT $\left(G_{1 / 2}=+17.3 \pm 0.6 \mathrm{mV} ; n=5\right)$. There was no significant change in the half-maximal voltage dependence of steady-state inactivation gating $\left(\mathrm{Vi}_{1 / 2}=-24.4 \pm 0.8\right.$ and $-25.9 \pm 0.5 \mathrm{mV}$ for Kv2.1- $\Delta 55-71$ and WT, respectively; $n=5$ ) (Fig. $8 C, D$ ). Moreover, the Kv2.1- $\Delta 55-71$ phenotype resembled that of dephosphorylated Kv2.1 and $\Delta$ C416 in the lack of appreciable response to intracellular AP dialysis on the voltage dependence of activation and inactivation gating $\left(\Delta G_{1 / 2}=-6.1 \mathrm{mV}\right.$ and $\left.\Delta V \mathrm{i}_{1 / 2}=-2.4 \mathrm{mV} ; n=5\right)$ relative to that observed for $\operatorname{Kv} 2.1-\mathrm{WT}\left(\Delta G_{1 / 2}=-37.4 \mathrm{mV}\right.$ and $\left.\Delta V \mathrm{i}_{1 / 2}=-32.3 \mathrm{mV} ; n=5\right)$. These results indicate that $\mathrm{N} / \mathrm{C}$ interaction is required to mediate the effects of C-terminal phosphorylation on voltage-dependent gating of Kv2.1 channels.

\section{Discussion}

Intracellular trafficking of $\mathrm{Kv}$ channels is regulated by a diverse set of determinants (Vacher et al., 2006). Here, we found that interaction between short segments within the Kv2.1 cytoplasmic $\mathrm{N}$ and $\mathrm{C}$ termini regulates its intracellular trafficking and surface expression. The critical C-terminal segment is highly charged, 


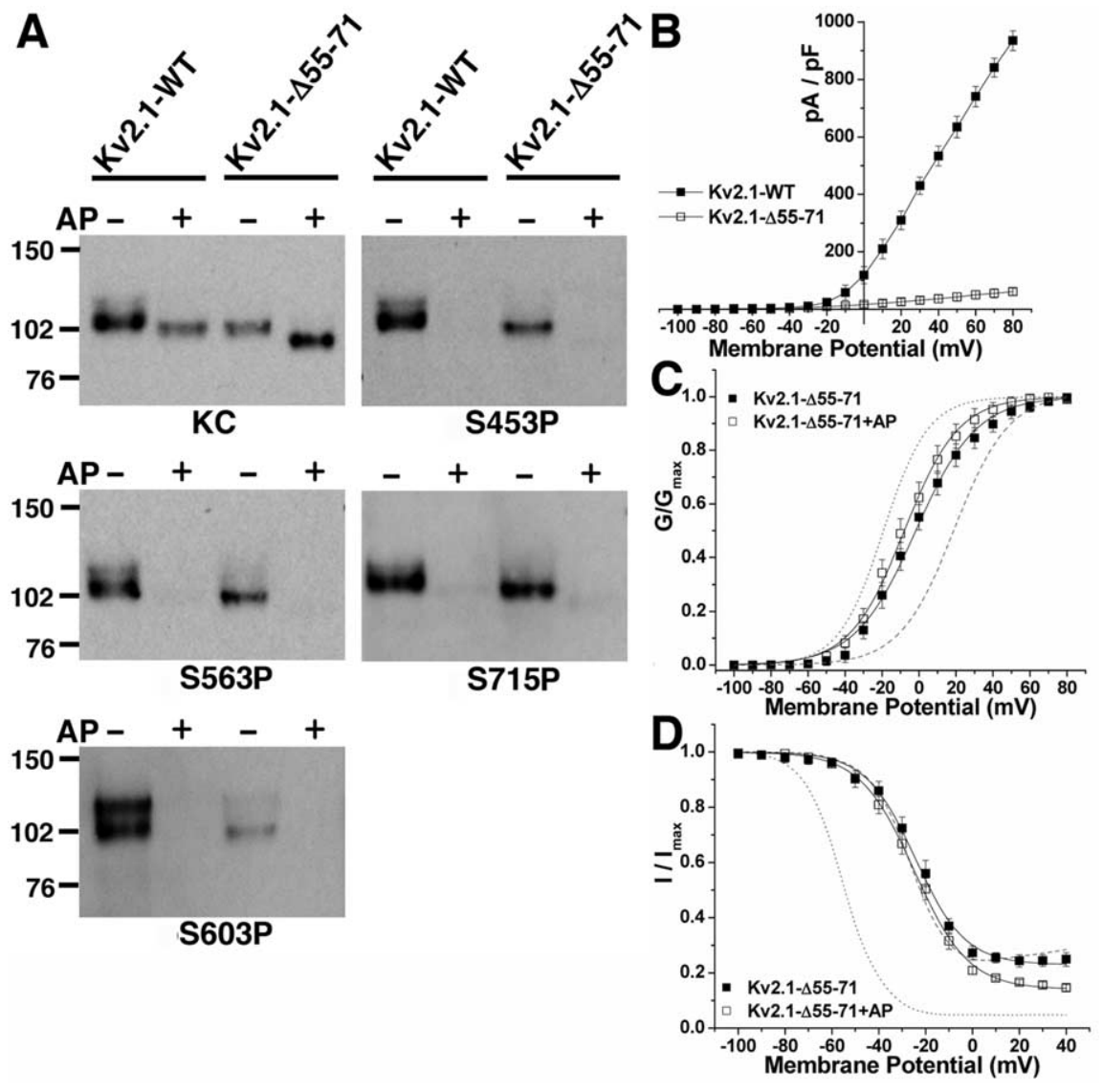

Figure 8. $\quad \mathrm{N} / \mathrm{C}$ interaction motifs regulate the phosphorylation-dependent modulation of Kv2.1 voltage-dependent gating. $\boldsymbol{A}$, The Kv2.1- $\Delta 55-71$ mutant is constitutively phosphorylated. HEK293 cell lysates from cells expressing Kv2.1-WT or Kv2.1$\Delta 55-71$ were digested without or with $\mathrm{AP}\left(100 \mathrm{U} / \mathrm{ml}\right.$ for $2 \mathrm{~h}$ at $\left.37^{\circ} \mathrm{C}\right)$ and subjected to immunoblot with anti-Kv2.1 antibody KC and phosphospecific anti-Kv2.1 antibodies S453P, S563P, S603P, and S715P, as detailed in Materials and Methods. Numbers to the left of each panel refer to mobility of prestained molecular weight standards in kilodaltons. Note that Kv2.1- $\Delta 55-71$ is constitutively phosphorylated at all four major phosphorylation sites. $\boldsymbol{B}$, Current density plot of whole-cell patch-clamp recordings of Kv2.1-WT and Kv2.1- $\Delta 55-71$. Data are presented as mean picoamperes per picofarad \pm SEM ( $n=5$ each). $C$, $\boldsymbol{D}$, Phosphorylation-dependent modulation of the voltage-dependent gating properties of Kv2.1 is abolished in the $\Delta 55-71 \mathrm{mu}-$ tant. Voltage-dependent activation $(\boldsymbol{C})$ and steady-state inactivation $(\boldsymbol{D})$ curves for $\Delta 55-71$ with or without intracellular AP dialysis. Note that $\Delta 55-71$ behaves quite similar to the Kv2.1 tailless mutant $\Delta$ C416 (Fig. 2C) in that it exhibits a relatively hyperpolarized G-V curve and lack of robust response to AP dialysis relative to Kv2.1-WT (gray lines: - AP, dashed; + AP, dotted).

overall quite acidic, and located near the S6 transmembrane segment. Deletion of a similarly localized acidic segment in Kv1 channels leads to misfolded channels retained in the RER (Manganas et al., 2001b). C-terminal phosphorylation can also affect Kv1 channel trafficking (Yang et al., 2007). Although the Kv2.1 C terminus is extensively phosphorylated (Park et al., 2006), phosphorylation does not appear to be a major determinant of its trafficking, because phosphorylation site mutants exhibit trafficking properties similar to WT Kv2.1 (Park et al., 2006). Moreover, although Kv2.1 phosphorylation differs between COS and HEK (Mohapatra and Trimmer, 2006; Park et al., 2007), Kv2.1 trafficking does not. The precise mechanism whereby N/Cterminal interaction promotes Kv2.1 surface expression is not known. The existence of an RER retention signal in the Kv2.1 N or $\mathrm{C}$ terminus that is masked on interaction, as occurs in $\mathrm{K}_{\mathrm{ATP}}$ channels (Zerangue et al., 1999) appears unlikely, as a Kv2.1 mutant with deleted $\mathrm{N}$ and $\mathrm{C}$ termini $(\Delta \mathrm{N} 139-\Delta \mathrm{C} 416)$ is not efficiently expressed on the cell surface, and is not rescued by soluble $\mathrm{N}$ - or C-terminal fragments.

The intracellular trafficking of Kv1 and $\mathrm{Kv} 4$ channels is profoundly affected by association of their $\mathrm{N}$-terminal $\mathrm{T} 1$ domains with auxiliary subunits (Shi et al., 1996; Shibata et al., 2003). Homology modeling of the Kv2.1 T1 domain with known structures of Kv1, Kv3, and Kv4 T1 domains revealed a Kv2 family-specific loop (residues 55-71), which we found is critical for interaction with C-terminal residues $444-$ 477. The Kv2.1-specific T1 domain segment 55-71 that mediates interaction with the Kv2.1 C terminus is not required for efficient tetramerization, but is obligatory for efficient cell surface expression and modulation of voltage-dependent gating by C-terminal phosphorylation (Figs. 7, $8)$. This region is located near the distal loop of the T1 domain (Fig. 7), which in Kv1.2 channels binds cytoplasmic auxiliary $\mathrm{Kv} \beta 2$ subunits (Gulbis et al., 2000). $\mathrm{Kv} 1.2 / \mathrm{Kv} \beta 2$ interaction shares similarities to Kv2.1 N/C interaction in not being required for channel tetramerization, but being necessary for efficient trafficking (Shi et al., 1996; Campomanes et al., 2002). It is intriguing that replacement of the Kv2.1 T1 domain with that of the Drosophila Shaker channel yielded functional expression in Xenopus oocytes ( $\mathrm{Li}$ et al., 1992). However, analyses of the trafficking efficiency and voltage-dependent gating characteristics of this chimeric channel were not performed, and it remains an open question as to the precise impact of this foreign T1 domain on Kv2.1 trafficking and gating.

The soluble Kv2.1 N-terminal fragment does not efficiently tetramerize, but instead appears to form larger order oligomers (Fig. 4 ), although interaction with other cellular proteins cannot be ruled out. This is distinct from the behavior of N-terminal fragments of Kv1 (Pfaffinger and DeRubeis, 1995; Kreusch et al., 1998) and Kv3 (Bixby et al., 1999) channels, which efficiently tetramerize. Kv4 N-terminal fragments also aggregate (Scannevin et al., 2004), and interaction with cytoplasmic auxiliary KChIP subunits, which promotes efficient Kv4 trafficking (An et al., 2000; Shibata et al., 2003), prevents aggregation and promotes formation of stable tetramers (Scannevin et al., 2004; Zhou et al., 2004; Wang et al., 2007). However, unlike the Kv2.1 T1 domain segment that mediates N/C interaction, deletion of the KChIP binding domain leads to increased trafficking of Kv4 channels (Bahring et al., 2001; Shibata et al., 2003). Existing biochemical evidence suggests that Kv2.1 channels do not have cytoplasmic auxiliary subunits (Chung and Li, 2005). This suggests that Kv2.1 N/C interaction may serve to accomplish what in other $\mathrm{Kv}$ channels requires association with auxiliary subunits. N/C interaction is specific to fragments from Kv2.1 (Fig. 1; supplemental Fig. 1, available at www.jneurosci.org as supplemental material) and, based on sequence similarities within the interaction domains, can presumably be extended to Kv2.2, but not to members of other Kv families (supplemental Fig. 1, available at www.jneurosci.org as supplemental material). The Kv2 family T1 domain is the only T1 domain for which structural information is lacking, perhaps because of the lack of a tetrameric structure when expressed in the absence of the $\mathrm{C}$ 
terminus. Coexpression of soluble (or fused) $\mathrm{N}$ and $\mathrm{C}$ termini may rescue this deficit, as observed for other $\mathrm{K}^{+}$channels (Nishida and MacKinnon, 2002; Scannevin et al., 2004; Zhou et al., 2004; Pegan et al., 2005; Wang et al., 2007), and allow for structural insights into these important domains.

Interdomain cytoplasmic interactions are common among polytopic membrane proteins such as ion channels and receptors (Sun et al., 1995; Schulteis et al., 1996; Gordon et al., 1997; Naren et al., 1999; Ikemoto and Yamamoto, 2002). The activation gating of a number of ion channels, especially whose gating is influenced by intracellular ligand binding [e.g., cyclic nucleotide gated channels (Gordon et al., 1997; Varnum and Zagotta, 1997; Zheng et al., 2003) and cystic fibrosis transmembrane conductance regulator channels (Naren et al., 1999)], involves N/C interaction. Previous mutational analyses of the effects of $\mathrm{N}$ - and C-terminal deletions (VanDongen et al., 1990), point mutations (Ju et al., 2003), and chimeras (Scholle et al., 2004; Mohapatra and Trimmer, 2006) suggested a role for $\mathrm{N} / \mathrm{C}$ interaction in regulating Kv2.1 voltage-dependent activation, and a direct interaction between Kv2.1 N and $\mathrm{C}$ termini has been suggested from in vitro binding studies (Bentley et al., 1999). Voltage-dependent Kv2.1 activation is also profoundly affected by extensive in vivo Kv2.1 C-terminal phosphorylation (Park et al., 2006). Here, we found that mutating the N-terminal motif that mediates Kv2.1 N/C interaction yields a channel that behaves as if it were dephosphorylated, although biochemical and immunochemical analyses suggest that C-terminal phosphorylation is intact (Fig. 8). This suggests that phosphorylation-dependent modulation of Kv2.1 requires N/C interaction. Recent studies using fluorescence resonance energy transfer demonstrated N/C interaction within Kv2.1 and suggested dynamic changes in this interaction during voltage-dependent gating (Kobrinsky et al., 2006). Analyses of the effects of altering phosphorylation state on Kv2.1 N/C interaction using such sensitive techniques may clarify the role of C-terminal phosphorylation in regulating this interaction and channel gating. That WT gating properties are restored to truncated channels on coexpression of a soluble $\mathrm{C}$ terminus is intriguing in that most models of $\mathrm{Kv}$ channel gating (Tombola et al., 2006) suggest a role of the $C$ terminus in gating via direct connection with transmembrane segment S6, lacking in tailless Kv2.1 reconstituted with its missing $\mathrm{C}$ terminus. Only one of the phosphorylation sites modulating Kv2.1 gating (S453) is within the C-terminal motif (amino acids 444-477) identified as mediating $\mathrm{N} / \mathrm{C}$ interaction, and AP digestion of the soluble $\mathrm{N}$ and $\mathrm{C}$ termini does not affect our ability to co-IP these fragments. Changes in C-terminal phosphorylation may modulate N/C interaction sufficiently to alter gating but not to disrupt the interaction altogether.

Our co-IP experiments suggest that a Kv2.1-specific membrane proximal segment (residues 444-477) in the cytoplasmic $\mathrm{C}$ terminus is the primary determinant for N-terminal interaction (Figs. 6, 7). Previous experiments showed that a much larger C-terminal fragment (the Cla domain, incorporating residues 411521 ) could interact with the Kv2.1 $\mathrm{N}$ terminus in vitro (Tsuk et al., 2005), and could also interact with soluble $N$-ethylmaleimidesensitive factor attachment protein receptor (SNARE) proteins (Singer-Lahat et al., 2007, 2008). However, whether the precise determinants for SNARE interaction overlap with the 34 aa residue motif we found critical for interaction with the $\mathrm{N}$ terminus is not known. The recent determination of the three-dimensional structure of intact tetrameric human Kv2.1 by electron microscopy and single-particle image analysis shows extra cytoplasmic volume surrounding the presumed site of the tetramerized T1 domains that appears to correspond to the $\mathrm{C}$ termini of the four Kv2.1 subunits (Adair et al., 2008). The solvent-exposed external surface of this domain could mediate interactions with cellular proteins, such as SNAREs (Singer-Lahat et al., 2007, 2008), whereas the internal face of the C-terminal structure interacts with the T1 domains (Adair et al., 2008).

Coexpression of tailless Kv2.1 with the soluble C-terminal fragment is able to reconstitute most aspects of the Kv2.1-WT phenotype (efficient trafficking, normal voltage-dependent gating, modulation by phosphorylation) except clustered localization (Scannevin et al., 1996; Lim et al., 2000; O'Connell and Tamkun, 2005). These reconstituted channels have a uniform distribution typical of C-terminally truncated Kv2.1 (Scannevin et al., 1996; Lim et al., 2000), and Kv2.1 lacking normal levels of C-terminal phosphorylation (Misonou et al., 2004; Mohapatra and Trimmer, 2006), suggesting that association of the separate $C$ terminus with the channel proper via N/C interaction is not sufficient to mediate clustering. Alternatively, the excess-free $\mathrm{C}$ termini may act as dominant negatives by competing for a limited set of clustering sites. The mechanism of clustering is not known but is presumed to involve interaction of the $\mathrm{C}$ terminus of the channel with components of a perimeter fence that surrounds each cluster (O'Connell et al., 2006; Tamkun et al., 2007). The basis for the lack of clustering in the coexpressed and interacting Kv2.1 tailless mutant and soluble $\mathrm{C}$ terminus remains an open question.

\section{References}

Adair B, Nunn R, Lewis S, Dukes I, Philipson L, Yeager M (2008) Single particle image reconstruction of the human recombinant Kv2.1 channel. Biophys J 94:2106-2114.

An WF, Bowlby MR, Betty M, Cao J, Ling HP, Mendoza G, Hinson JW, Mattsson KI, Strassle BW, Trimmer JS, Rhodes KJ (2000) Modulation of A-type potassium channels by a family of calcium sensors. Nature 403:553-556.

Antonucci DE, Lim ST, Vassanelli S, Trimmer JS (2001) Dynamic localization and clustering of dendritic Kv2.1 voltage-dependent potassium channels in developing hippocampal neurons. Neuroscience 108:69-81.

Bahring R, Dannenberg J, Peters HC, Leicher T, Pongs O, Isbrandt D (2001) Conserved Kv4 N-terminal domain critical for effects of Kv channelinteracting protein 2.2 on channel expression and gating. J Biol Chem 276:23888-23894.

Bentley GN, Brooks MA, O’Neill CA, Findlay JB (1999) Determinants of potassium channel assembly localised within the cytoplasmic C-terminal domain of Kv2.1. Biochim Biophys Acta 1418:176-184.

Bixby KA, Nanao MH, Shen NV, Kreusch A, Bellamy H, Pfaffinger PJ, Choe S (1999) $\mathrm{Zn}^{2+}$-binding and molecular determinants of tetramerization in voltage-gated $\mathrm{K}^{+}$channels. Nat Struct Biol 6:38-43.

Campomanes CR, Carroll KI, Manganas LN, Hershberger ME, Gong B, Antonucci DE, Rhodes KJ, Trimmer JS (2002) Kv beta subunit oxidoreductase activity and Kv1 potassium channel trafficking. J Biol Chem 277:8298-8305.

Chung JJ, Li M (2005) Biochemical characterization of the native Kv2.1 potassium channel. FEBS J 272:3743-3755.

Du J, Haak LL, Phillips-Tansey E, Russell JT, McBain CJ (2000) Frequencydependent regulation of rat hippocampal somato-dendritic excitability by the $\mathrm{K}^{+}$channel subunit Kv2.1. J Physiol (Lond) 522:19-31.

Gong J, Xu J, Bezanilla M, van Huizen R, Derin R, Li M (1999) Differential stimulation of PKC phosphorylation of potassium channels by ZIP1 and ZIP2. Science 285:1565-1569.

Gordon SE, Varnum MD, Zagotta WN (1997) Direct interaction between amino- and carboxyl-terminal domains of cyclic nucleotide-gated channels. Neuron 19:431-441.

Gu C, Jan YN, Jan LY (2003) A conserved domain in axonal targeting of Kv1 (Shaker) voltage-gated potassium channels. Science 301:646-649.

Guex N, Peitsch MC (1997) SWISS-MODEL and the Swiss-PdbViewer: an environment for comparative protein modeling. Electrophoresis 18:2714-2723. 
Gulbis JM, Zhou M, Mann S, MacKinnon R (2000) Structure of the cytoplasmic beta subunit-T1 assembly of voltage-dependent $\mathrm{K}^{+}$channels. Science 289:123-127.

Gutman GA, Chandy KG, Grissmer S, Lazdunski M, McKinnon D, Pardo LA, Robertson GA, Rudy B, Sanguinetti MC, Stuhmer W, Wang X (2005) International Union of Pharmacology. LIII. Nomenclature and molecular relationships of voltage-gated potassium channels. Pharmacol Rev 57:473-508

Hwang PM, Fotuhi M, Bredt DS, Cunningham AM, Snyder SH (1993) Contrasting immunohistochemical localizations in rat brain of two novel $\mathrm{K}^{+}$ channels of the Shab subfamily. J Neurosci 13:1569-1576.

Ikemoto N, Yamamoto T (2002) Regulation of calcium release by interdomain interaction within ryanodine receptors. Front Biosci 7:d671-d683.

Jerng HH, Pfaffinger PJ, Covarrubias M (2004) Molecular physiology and modulation of somatodendritic A-type potassium channels. Mol Cell Neurosci 27:343-369.

Ju M, Stevens L, Leadbitter E, Wray D (2003) The roles of N- and C-terminal determinants in the activation of the Kv2.1 potassium channel. J Biol Chem 278:12769-12778.

Kobrinsky E, Stevens L, Kazmi Y, Wray D, Soldatov NM (2006) Molecular rearrangements of the Kv2.1 potassium channel termini associated with voltage gating. J Biol Chem 281:19233-19240.

Kreusch A, Pfaffinger PJ, Stevens CF, Choe S (1998) Crystal structure of the tetramerization domain of the Shaker potassium channel. Nature 392:945-948.

Li M, Jan YN, Jan LY (1992) Specification of subunit assembly by the hydrophilic amino-terminal domain of the Shaker potassium channel. Science 257:1225-1230.

Li Y, Um SY, McDonald TV (2006) Voltage-gated potassium channels: regulation by accessory subunits. Neuroscientist 12:199-210.

Lim ST, Antonucci DE, Scannevin RH, Trimmer JS (2000) A novel targeting signal for proximal clustering of the Kv2.1 $\mathrm{K}^{+}$channel in hippocampal neurons. Neuron 25:385-397.

Long SB, Campbell EB, Mackinnon R (2005) Crystal structure of a mammalian voltage-dependent Shaker family $\mathrm{K}^{+}$channel. Science 309:897-903.

Malin SA, Nerbonne JM (2002) Delayed rectifier $\mathrm{K}^{+}$currents, IK, are encoded by Kv2 alpha-subunits and regulate tonic firing in mammalian sympathetic neurons. J Neurosci 22:10094-10105.

Manganas LN, Trimmer JS (2000) Subunit composition determines Kv1 potassium channel surface expression. J Biol Chem 275:29685-29693.

Manganas LN, Wang Q, Scannevin RH, Antonucci DE, Rhodes KJ, Trimmer JS (2001a) Identification of a trafficking determinant localized to the Kv1 potassium channel pore. Proc Natl Acad Sci USA 98:14055-14059.

Manganas LN, Akhtar S, Antonucci DE, Campomanes CR, Dolly JO, Trimmer JS (2001b) Episodic ataxia type-1 mutations in the Kv1.1 potassium channel display distinct folding and intracellular trafficking properties. J Biol Chem 276:49427-49434.

Minor DL, Lin YF, Mobley BC, Avelar A, Jan YN, Jan LY, Berger JM (2000) The polar T1 interface is linked to conformational changes that open the voltage-gated potassium channel. Cell 102:657-670.

Misonou H, Mohapatra DP, Park EW, Leung V, Zhen D, Misonou K, Anderson AE, Trimmer JS (2004) Regulation of ion channel localization and phosphorylation by neuronal activity. Nat Neurosci 7:711-718.

Misonou H, Mohapatra DP, Menegola M, Trimmer JS (2005) Calcium- and metabolic state-dependent modulation of the voltage-dependent Kv2.1 channel regulates neuronal excitability in response to ischemia. J Neurosci 25:11184-11193.

Misonou H, Menegola M, Mohapatra DP, Guy LK, Park KS, Trimmer JS (2006) Bidirectional activity-dependent regulation of neuronal ion channel phosphorylation. J Neurosci 26:13505-13514.

Mohapatra DP, Trimmer JS (2006) The Kv2.1 C terminus can autonomously transfer Kv2.1-like phosphorylation-dependent localization, voltage-dependent gating, and muscarinic modulation to diverse $\mathrm{Kv}$ channels. J Neurosci 26:685-695.

Murakoshi H, Trimmer JS (1999) Identification of the Kv2.1 $\mathrm{K}^{+}$channel as a major component of the delayed rectifier $\mathrm{K}^{+}$current in rat hippocampal neurons. J Neurosci 19:1728-1735.

Murakoshi H, Shi G, Scannevin RH, Trimmer JS (1997) Phosphorylation of the $\mathrm{Kv} 2.1 \mathrm{~K}^{+}$channel alters voltage-dependent activation. Mol Pharmacol 52:821-828.

Nanao MH, Zhou W, Pfaffinger PJ, Choe S (2003) Determining the basis of channel-tetramerization specificity by $\mathrm{x}$-ray crystallography and a sequence-comparison algorithm: Family Values (FamVal). Proc Natl Acad Sci USA 100:8670-8675.

Naren AP, Cormet-Boyaka E, Fu J, Villain M, Blalock JE, Quick MW, Kirk KL (1999) CFTR chloride channel regulation by an interdomain interaction. Science 286:544-548.

Nishida M, MacKinnon R (2002) Structural basis of inward rectification: cytoplasmic pore of the $\mathrm{G}$ protein-gated inward rectifier GIRK1 at $1.8 \mathrm{~A}$ resolution. Cell 111:957-965.

O'Connell KM, Tamkun MM (2005) Targeting of voltage-gated potassium channel isoforms to distinct cell surface microdomains. J Cell Sci 118:2155-2166.

O'Connell KM, Rolig AS, Whitesell JD, Tamkun MM (2006) Kv2.1 potassium channels are retained within dynamic cell surface microdomains that are defined by a perimeter fence. J Neurosci 26:9609-9618.

Papazian DM (1999) Potassium channels: some assembly required. Neuron 23:7-10.

Park KS, Mohapatra DP, Misonou H, Trimmer JS (2006) Graded regulation of the Kv2.1 potassium channel by variable phosphorylation. Science 313:976-979.

Park KS, Mohapatra DP, Trimmer JS (2007) Proteomic analyses of Kv2.1 channel phosphorylation sites determining cell background-specific differences in function. Channels 1:59-61.

Pegan S, Arrabit C, Zhou W, Kwiatkowski W, Collins A, Slesinger PA, Choe S (2005) Cytoplasmic domain structures of Kir2.1 and Kir3.1 show sites for modulating gating and rectification. Nat Neurosci 8:279-287.

Pfaffinger PJ, DeRubeis D (1995) Shaker $\mathrm{K}^{+}$channel T1 domain selftetramerizes to a stable structure. J Biol Chem 270:28595-28600.

Pongs O (1999) Voltage-gated potassium channels: from hyperexcitability to excitement. FEBS Lett 452:31-35.

Rhodes KJ, Keilbaugh SA, Barrezueta NX, Lopez KL, Trimmer JS (1995) Association and colocalization of $\mathrm{K}^{+}$channel $\alpha$ - and $\beta$-subunit polypeptides in rat brain. J Neurosci 15:5360-5371.

Rhodes KJ, Carroll KI, Sung MA, Doliveira LC, Monaghan MM, Burke SL, Strassle BW, Buchwalder L, Menegola M, Cao J, An WF, Trimmer JS (2004) KChIPs and Kv4 alpha subunits as integral components of A-type potassium channels in mammalian brain. J Neurosci 24:7903-7915.

Scannevin RH, Murakoshi H, Rhodes KJ, Trimmer JS (1996) Identification of a cytoplasmic domain important in the polarized expression and clustering of the Kv2.1 $\mathrm{K}^{+}$channel. J Cell Biol 135:1619-1632.

Scannevin RH, Wang K, Jow F, Megules J, Kopsco DC, Edris W, Carroll KC, Lü Q, Xu W, Xu Z, Katz AH, Olland S, Lin L, Taylor M, Stahl M, Malakian K, Somers W, Mosyak L, Bowlby MR, Chanda P, et al. (2004) Two $\mathrm{N}$-terminal domains of $\mathrm{Kv} 4 \mathrm{~K}(+)$ channels regulate binding to and modulation by KChIP1. Neuron 41:587-598.

Scholle A, Zimmer T, Koopmann R, Engeland B, Pongs O, Benndorf K (2004) Effects of Kv1.2 intracellular regions on activation of Kv2.1 channels. Biophys J 87:873-882.

Schrader LA, Anderson AE, Mayne A, Pfaffinger PJ, Sweatt JD (2002) PKA modulation of Kv4.2-encoded A-type potassium channels requires formation of a supramolecular complex. J Neurosci 22:10123-10133.

Schulteis CT, Nagaya N, Papazian DM (1996) Intersubunit interaction between amino- and carboxyl-terminal cysteine residues in tetrameric shaker $\mathrm{K}^{+}$channels. Biochemistry 35:12133-12140.

Schwede T, Kopp J, Guex N, Peitsch MC (2003) SWISS-MODEL: an automated protein homology-modeling server. Nucleic Acids Res 31:3381-3385.

Sewing S, Roeper J, Pongs O (1996) Kv beta 1 subunit binding specific for shaker-related potassium channel alpha subunits. Neuron 16:455-463.

Sharma N, D’Arcangelo G, Kleinlaus A, Halegoua S, Trimmer JS (1993) Nerve growth factor regulates the abundance and distribution of $\mathrm{K}^{+}$ channels in PC12 cells. J Cell Biol 123:1835-1843.

Shi G, Nakahira K, Hammond S, Rhodes KJ, Schechter LE, Trimmer JS (1996) Beta subunits promote $\mathrm{K}^{+}$channel surface expression through effects early in biosynthesis. Neuron 16:843-852.

Shibata R, Misonou H, Campomanes CR, Anderson AE, Schrader LA, Doliveira LC, Carroll KI, Sweatt JD, Rhodes KJ, Trimmer JS (2003) A fundamental role for KChIPs in determining the molecular properties and trafficking of Kv4.2 potassium channels. J Biol Chem 278:36445-36454.

Singer-Lahat D, Sheinin A, Chikvashvili D, Tsuk S, Greitzer D, Friedrich R, Feinshreiber L, Ashery U, Benveniste M, Levitan ES, Lotan I (2007) $\mathrm{K}^{+}$ 
channel facilitation of exocytosis by dynamic interaction with syntaxin. J Neurosci 27:1651-1658.

Singer-Lahat D, Chikvashvili D, Lotan I (2008) Direct interaction of endogenous kv channels with syntaxin enhances exocytosis by neuroendocrine cells. PLoS ONE 3:e1381.

Sun W, Barchi RL, Cohen SA (1995) Probing sodium channel cytoplasmic domain structure. Evidence for the interaction of the rSkM1 amino and carboxyl termini. J Biol Chem 270:22271-22276.

Tamkun MM, O'Connell KM, Rolig AS (2007) A cytoskeletal-based perimeter fence selectively corrals a sub-population of cell surface Kv2.1 channels. J Cell Sci 120:2413-2423.

Tiffany AM, Manganas LN, Kim E, Hsueh YP, Sheng M, Trimmer JS (2000) PSD-95 and SAP97 exhibit distinct mechanisms for regulating $\mathrm{K}^{+}$channel surface expression and clustering. J Cell Biol 148:147-158.

Tombola F, Pathak MM, Isacoff EY (2006) How does voltage open an ion channel? Annu Rev Cell Dev Biol 22:23-52.

Trimmer JS (1991) Immunological identification and characterization of a delayed rectifier $\mathrm{K}^{+}$channel polypeptide in rat brain. Proc Natl Acad Sci USA 88:10764-10768.

Tsuk S, Michaelevski I, Bentley GN, Joho RH, Chikvashvili D, Lotan I (2005) Kv2.1 channel activation and inactivation is influenced by physical interactions of both syntaxin $1 \mathrm{~A}$ and the syntaxin $1 \mathrm{~A} /$ soluble $\mathrm{N}$-ethylmaleimide-sensitive factor-25 (t-SNARE) complex with the C terminus of the channel. Mol Pharmacol 67:480-488.

Vacher H, Misonou H, Trimmer JS (2006) Determinants of voltage-gated potassium channel distribution in mammalian neurons. In: Protein traf- ficking in neurons (Bean AJ, ed), pp 244-270. London: Elsevier Academic.

VanDongen AM, Frech GC, Drewe JA, Joho RH, Brown AM (1990) Alteration and restoration of $\mathrm{K}^{+}$channel function by deletions at the $\mathrm{N}$ - and C-termini. Neuron 5:433-443.

Varnum MD, Zagotta WN (1997) Interdomain interactions underlying activation of cyclic nucleotide-gated channels. Science 278:110-113.

Wang H, Yan Y, Liu Q, Huang Y, Shen Y, Chen L, Chen Y, Yang Q, Hao Q, Wang K, Chai J (2007) Structural basis for modulation of Kv4 K ${ }^{+}$channels by auxiliary KChIP subunits. Nat Neurosci 10:32-39.

Yang JW, Vacher H, Park KS, Clark E, Trimmer JS (2007) Traffickingdependent phosphorylation of Kv1.2 regulates voltage-gated potassium channel cell surface expression. Proc Natl Acad Sci USA 104:20055-20060.

Yu W, Xu J, Li M (1996) NAB domain is essential for the subunit assembly of both alpha-alpha and alpha-beta complexes of shaker-like potassium channels. Neuron 16:441-453.

Zerangue N, Schwappach B, Jan YN, Jan LY (1999) A new ER trafficking signal regulates the subunit stoichiometry of plasma membrane K(ATP) channels. Neuron 22:537-548.

Zheng J, Varnum MD, Zagotta WN (2003) Disruption of an intersubunit interaction underlies $\mathrm{Ca}^{2+}$-calmodulin modulation of cyclic nucleotidegated channels. J Neurosci 23:8167-8175.

Zhou W, Qian Y, Kunjilwar K, Pfaffinger PJ, Choe S (2004) Structural insights into the functional interaction of KChIP1 with Shal-type $\mathrm{K}^{+}$channels. Neuron 41:573-586. 